Florida International University FIU Digital Commons

$11-27-2001$

\title{
Identification of genes downstream of endothelin-3 signaling: characterization of WSB1 and SPC12
}

Aniveny Ayala

Florida International University

DOI: $10.25148 /$ etd.FI14032380

Follow this and additional works at: https://digitalcommons.fiu.edu/etd

Part of the Biology Commons

\section{Recommended Citation}

Ayala, Aniveny, "Identification of genes downstream of endothelin-3 signaling: characterization of WSB1 and SPC12" (2001). FIU Electronic Theses and Dissertations. 1349.

https://digitalcommons.fiu.edu/etd/1349 
FLORIDA INTERNATIONAL UNIVERSITY

Miami, Florida

IDENTIFICATION OF GENES DOWNSTREAM OF ENDOTHELIN-3 SIGNALING:

CHARACTERIZATION OF WSB1 AND SPC12

A thesis submitted in partial fulfillment of the

requirements for the degree of

MASTER OF SCIENCE

in

BIOLOGY

by

Aniveny Ayala

2001 
To: Dean Arthur W. Herriott

College of Arts and Sciences

This thesis, written by Aniveny Ayala, and entitled Identification of genes downstream of Endothelin-3 signaling: Characterization of WSB1 and SPC12, having been approved in respect to style and intellectual content, is referred to you for judgment.

We have read this thesis and recommend that it be approved.

Keith Condon, $\mathrm{PhD}$

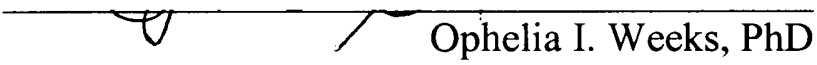

Lidia Kos, PhD, Major Professor

Date of Defense: November 27, 2001

The thesis of Aniveny Ayala is approved.

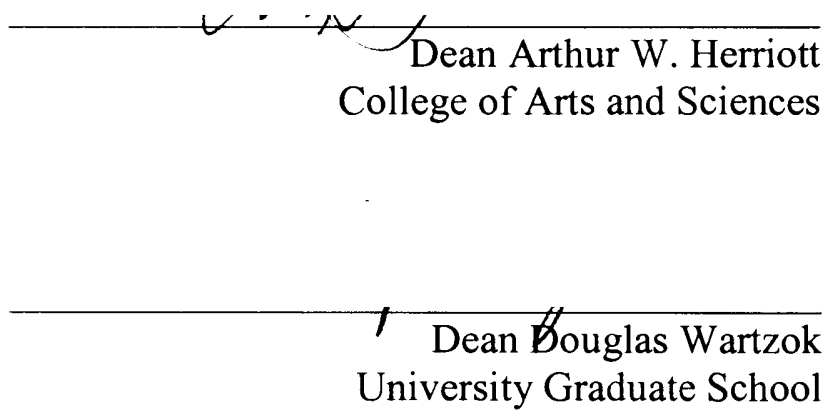

Florida International University, 2001 


\section{DEDICATION}

To my parents, for always expecting the best from me. To my husband, for being there when most needed. To Lidia, for being more than my mentor. 


\section{ACKNOWLEDGMENTS}

I wish to acknowledge my major professor and mentor, Dr. Lidia Kos for her continuous support, for her guidance, for having great confidence in my abilities, and for being an exceptional mentor and a great friend. I also wish to acknowledge my committee members, Dr. Ophelia I. Weeks and Dr. Keith Condon, for their most appreciated patience and help.

I would also like to acknowledge my labmates Sean Mandat for establishing numerous primary neural tube cultures and Avner Ittah for carrying out Differential Display RT-PCR, a valuable technique used during the development of this project;

all my other labmates: Rita, Kalai, Armando, Erasmo, Sonia, Larry, Enrique and Roman for the fun time we all had working together; and Claude, for being here, with me, throughout these years and forever. 


\begin{abstract}
OF THE THESIS
IDENTIFICATION OF GENES DOWNSTREAM OF ENDOTHELIN-3 SIGNALING:
\end{abstract}

CHARACTERIZATION OF WSB1 AND SPC12

by

Aniveny Ayala

Florida International University, 2001

Miami, Florida

Professor Lidia Kos, Major Professor

Signaling of endothelin-3 (Edn3) through its receptor, endothelin receptor B $(\mathrm{Ednr} B)$, has been shown to be indispensable for the development of certain neural crest derivatives. Since no research has been directed to investigate what the downstream targets of this signaling pathway are, the purpose of this study was to identify and characterize genes that are transcriptionally regulated by Edn3 signaling.

Data from Differential Display RT-PCR of Edn-3 induced cDNA vs. non-induced cDNA obtained from primary neural crest cultures was analyzed. Thirty bands that were differentially expressed were sequenced and submitted for a homology search (BLAST). Among the genes identified were WSBl (a member of the SOCS family of negative regulators) and SPC12 (the smallest subunit, 12kDa, of mammalian signal peptidase).

Using whole-mount in-situ hybridization, the expression patterns of EdnrB, WSB1 and SPC12 were characterized. WSB1 and SPC12 expression patterns were found to overlap with that of $\mathrm{EdnrB}$, suggesting that Edn3 might regulate the transcription of these genes in specific neural crest derived lineages. 


\section{TABLE OF CONTENTS}

\section{CHAPTER}

PAGE

I. INTRODUCTION.

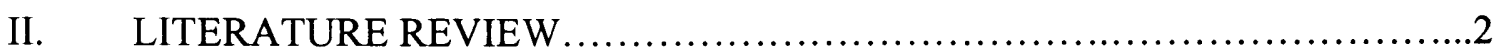

1. The neural crest............................................................

2. Endothelin-3 and Endothelin Receptor B...............................6

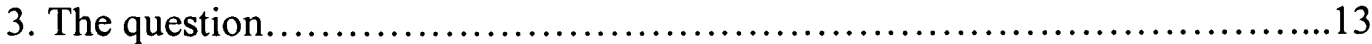

4. Preliminary data: Differential Display RT-PCR $\ldots \ldots \ldots \ldots \ldots \ldots \ldots \ldots \ldots \ldots \ldots$

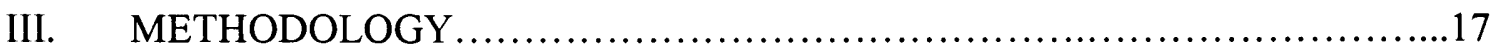

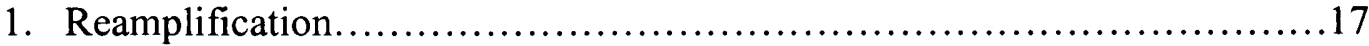

2. Preparation of Clones...................................................

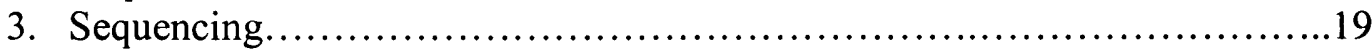

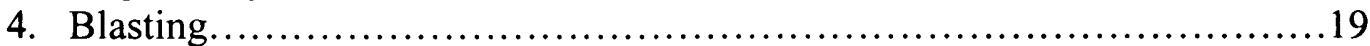

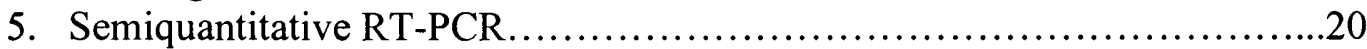

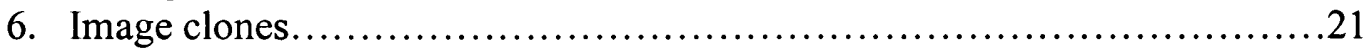

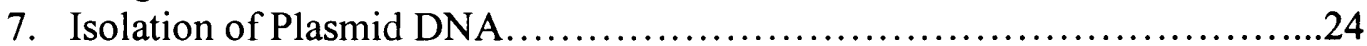

8. Riboprobe synthesis.................................................24

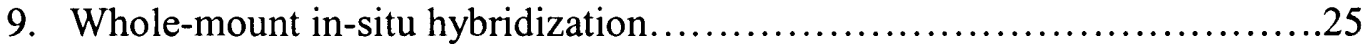

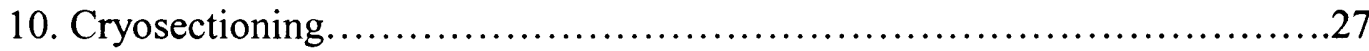

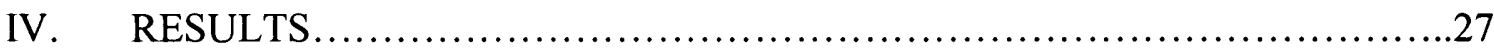

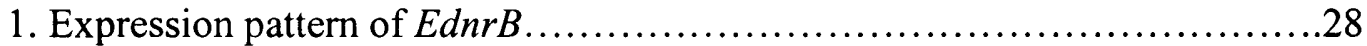

2. Identification of differentially expressed bands after induction with Edn3 .........................................................

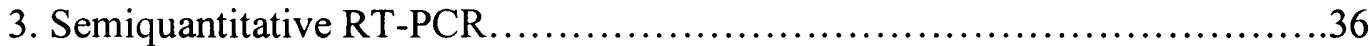

4. Characterization of $W S B 1$ and SPC12 using whole mount in-situ hybridization..............................................36

WSB1 expression pattern...........................................

SPC12 expression pattern.........................................

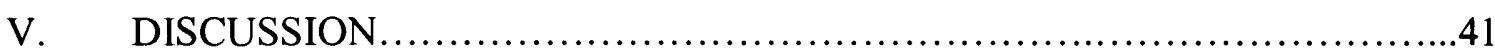

1. WSB1: A member of the SOCS family of negative regulators...............41

SOCS: Suppressors of cytokine signaling............................42

WSB1 and WSB2 .............................................46

WSB1 as a downstream target of Edn3 signaling ....................48

2. SPC12: the smallest subunit $(12 \mathrm{kDa})$ of the signal peptidase complex........50

3. Concluding Remarks................................................52

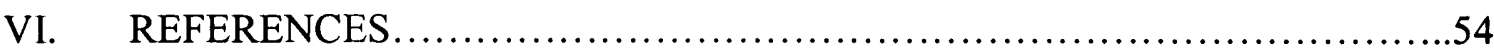

VII. APPENDICES........................................................62 


\section{LIST OF FIGURES}

\section{FIGURE}

PAGE

1. The Neural Crest............................................................ 3

2. Differential Display RT-PCR Gel...................................... 18

3. EdnrB expression pattern............................................. 29

4. Semiquantitative RT-PCR of WSB1 ................................... 37

5. Semiquantitative RT-PCR of SPC12 .............................. 37

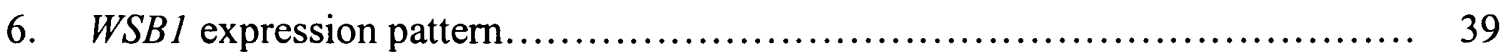

7. $\quad W S B 2$ expression pattern................................................ 40

8. $\quad S P C 12$ expression pattern............................................. 41

9. SOCS proteins....................................................... 45 


\section{INTRODUCTION}

Hirschsprung disease, a congenital disease characterized by lack of enteric ganglia and abnormal pigmentation pattern, has an incidence of 1:5000 in live births. People suffering from this disease show patches of skin with no pigment and develop megacolon as a result of the lack of innervation of their distal colon, indicating that the normal development of melanocytes (pigment producing cells) and enteric neurons has been altered. When the loci of genes mutated in Hirschsprung disease cases were identified, a new door for research was opened. Mutations in the loci coding for Endothelin-3 (Edn3) and its receptor, endothelin receptor $B(\mathrm{EdnrB})$ have since been held responsible for the aberrant phenotype and the signaling cascade they trigger considered essential for the proper development of the neural crest derivatives affected: melanocytes and enteric neurons. Many studies have demonstrated that addition of Edn3 to neural crest cultures increases proliferation and might favor differentiation of melanocytes but might also delay the differentiation of enteric neurons. In situ-hybridization studies of the expression pattern of $E d n r B$ and $E d n 3$ during embryogenesis have shown that cells from neural crest derived lineages express $E d n r B$ while $E d n 3$ is expressed in the environment through which these cells migrate. Transgenic studies attempting to rescue the wild type phenotype in mutant mice and rats (suffering from aganglionosis and pigmentation defects) had $E d n 3$ and $E d n r B$ loci placed under control of promoters such as dopamine- $\beta$-hydroxylase $(\mathrm{D} \beta \mathrm{H})$ and tetracycline-dependent transactivators (tTa or rtTA), respectively. They were able to determine that the Edn3/EdnrB signaling pathway is required from 10dpc (days post coitus) through $12.5 \mathrm{dpc}$ for the proper development of 
melanocytes and enteric neurons, which is consistent with previous understanding that melanoblasts and enteric neuroblasts begin their migration at about the same time. Moreover, Edn3 has been widely hypothesized to prevent immature differentiation of melanoblasts and neuroblasts until they reach their final destination. However, there has not been any active research investigating what the downstream targets of the Edn3/EdnrB signaling pathway are at a genetic and molecular level. Therefore, the purpose of study was to identify and characterize genes that are transcriptionally regulated by the biochemical pathway that Edn3 signaling elicits.

\section{LITERATURE REVIEW}

\section{The neural crest.}

During the early steps of embryogenesis, a large central region of the ectoderm (neural plate) thickens, rolls up into a tube and pinches off from the rest of the ectodermal sheet (epidermis) in a process known as neurulation. The newly formed neural tube gives rise to the central nervous system. Following neurulation, a distinct group of cells originates at the dorsalmost region of the neural tube, in between the neural plate and the epidermis. These cells, widely known as neural crest cells, delaminate and subsequently migrate throughout the vertebrate embryo, ultimately differentiating into numerous cell types along their characteristic migratory paths (Weston, 1963).

Neural crest cells (NCC) are initially pluripotent, yielding a large variety of derivatives including melanocytes, PNS neurons, glia, endocrine cells, bone, cartilage, chromaffin cells (reviewed by Le Douarin, 1993) and smooth muscle cells (reviewed by Anderson, 1997). However, their migratory behavior, together with the axial level at 


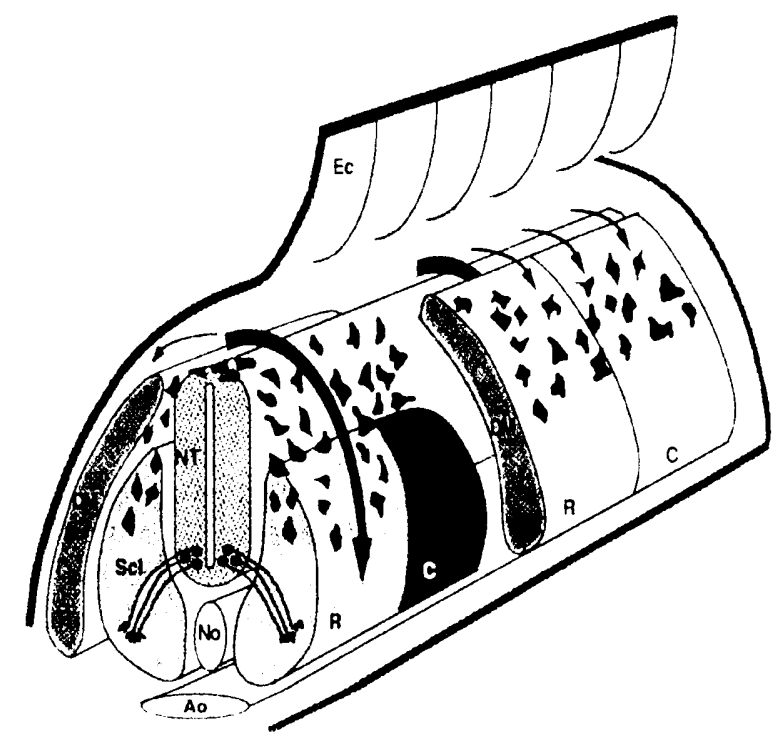

Figure 1. The Neural Crest. Diagramatic representation of the pathways that trunk neural crest cells (red) follow as they migrate from the dorsalmost region of the closing neural tube (NT). Also labeled are the ectoderm (Ec), dermomyotome (DM), sclerotome $(\mathrm{Scl})$, notochord $(\mathrm{No})$ and the developing aorta $(\mathrm{Ao})$ (from Gilbert, 2000).

which they arise and the final environment to which their cell derivatives localize are very closely related to their diversification (Le Douarin, 1986). For example, only cephalic neural crest forms the dermis, the membrane, cartilage, and bones of the skull vault, the skull basis, and the face (reviewed by Le Douarin, 1993). NCCs arising at the level of the hindbrain give rise to bone, cartilage and sensory neurons; and, smooth muscle, enteric neurons and endocrine cells (thyroid) are derivatives of vagal neural crest only (Le Douarin, 1982). Trunk NCCs differentiate into neurons and glia of sensory and autonomic ganglia (reviewed by Groves and Anderson, 1996) and follow two major pathways of migration, a ventral pathway through the rostral half of the somites and a 
dorsolateral pathway between the dermomyotome and the epidermis (Figure 1). Interestingly, melanocyte and glia (Schwann cells) are common derivatives of all axial levels.

Classical embryological studies performed mainly in avian embryos and clonal studies have shown that the process of commitment and differentiation of the neural crest cells is gradual, occurring as they migrate and reach their final targets (Le Douarin et al., 1994). A variety of precursors with more restricted potentials arise along the way, such as one committed only to giving rise to glia and melanocytes (Le Douarin et al., 1994; Gilbert, 1997).

The differentiation of NCCs involves an interaction between intrinsic and extrinsic signals. Extrinsic signals are usually molecules that affect cell-intrinsic regulators that in turn modulate how the cell might respond to the extracellular environment (Groves and Anderson, 1996). Extrinsic signals can act as instructive or permissive factors (Gilbert, 2000). Instructive factors directly influence the fate a cell acquires during its process of differentiation. An example of an instructive factor is BMP2 (bone morphogenetic factor 2), a member of the TGF $\beta$ (transforming growth factor- $\beta$ ) superfamily, which forms neurons at the expense of glial cells (Shah et al., 1996). Permissive factors, such as fibronectin, are those which provide the right environment without directing a cell to its final fate. For example, many cells require a solid substrate containing fibronectin or laminin in order to develop and grow. Fibronectin or laminin do not change the type of cell that is produced, but rather allow the cell to express what has been determined to be expressed. 
Intrinsic regulation is based on the activity of transcription factors which trigger a cascade of regulatory genes that can help specify cell fate in general, and cell identity more precisely (Jan and Jan, 1995).

An alteration of any of these regulatory pathways, such as naturally occurring or targeted mutations, could possibly cause a defect in various neural crest-derived cell lineages. Developmental biologists use these mutations to study the different steps involved in neural crest development: determination, migration, colonization, differentiation, and survival (Le Douarin et al., 1994). For instance, mutations present in genes encoding the c-Kit receptor tyrosine kinase and its extracellular ligand, Steel factor, result in fertility and hematopoietic defects as well as a 'patchy' phenotype, with patches of non-pigmented skin due to a failure in melanocyte precursors survival. Mice displaying these phenotypes have been named Dominant white spotting $(W)$ and Steel (Sl), respectively (Jackson, 1991). Mutations in the c-Ret receptor tyrosine kinase result in a megacolon phenotype due to a failure of the enteric ganglion neurons to populate the distal part of the gut (Schuchardt et al., 1994). Mutations in transcription factors such as Pax3 result in hypopigmentation, deafness, skeletal muscle and neural tube defects in Splotch mice ( $S p)$. A mutation in Mitf (also a transcription factor) has also been found to be responsible for hypopigmentation, deafness and retinal defects of Micropthalmia (Mi) mice (reviewed by Barsh, 1996; Jackson, 1997); and, mutations affecting the ErbB family of receptors (ErbB2 and ErbB3) and their ligand neuregulin-1, result in severe deficits of Schwann cells, another NCC derivative (Riethmacher et al., 1997).

All these mutations give us a sense of the importance of ligands and receptors in initiating a flow of biochemical reactions in order for the cell to respond to its 
surrounding environment. When one of these components is ablated, the signaling pathway to which it belongs is interrupted and, therefore, the normal development and differentiation of neural crest cells that are dependent on this pathway are also affected. Such is also the case of other two mutations that have been linked to neural crest derivatives defects. Lethal spotting $(l s)$ and piebald-lethal $(s l)$ mice are a result of mutations in the genes encoding Endothelin-3 (Edn3) and its receptor Endothelin receptor-B (EdnrB), respectively. Both mutant phenotypes are characterized by an abnormal pigmentation pattern with varying degrees of pigment loss and an aganglionic megacolon as a result of faulty melanocyte development and a defect in neural crest derived neuronal colonization of the hindgut (Baynash et al., 1994; Hosoda et al., 1994). $E d n r B$ mutations have also been identified in the rat as responsible for the spotting lethal condition (Ceccherini et al., 1995; Gariepy et al., 1996; Shin et al., 1997) and in the horse for the lethal white foal syndrome (Santschi et al., 1998). In humans, $E D N R B$, has been found to be mutated in $5 \%$ of the cases of Hirschsprung disease Type II characterized by almost identical phenotypes as those found in the mouse (Chakravarti, 1996;

Puffenberger et al., 1994). Homozygous mutations in EDN3 have been linked to a combination of Waardenburg syndrome Type II and Hirschsprung disease phenotype, referred to as Shah-Waardenburg syndrome. Patients with Shah-Waardenburg syndrome exhibit depigmentation as well as deafness (Hofstra et al., 1996).

\section{Endothelin-3 and Endothelin Receptor-B.}

Endothelins were first identified when a potent vasoconstrictor precursor peptide was isolated from culture supernatant of porcine aortic endothelial cells. This precursor 
peptide, preproendothelin, undergoes proteolytical processing producing a mature 21amino acid peptide (endothelin) that was found to be secreted by endothelial cells once they are exposed to various physical and chemical stimuli such as noradrenaline, thrombin, hypoxia and mechanical stretch (Yanagisawa et al..1, 1988).

The porcine preproendothelin cDNA was cloned and sequenced (Yanagisawa et al..1, 1988) and shortly after, both human (Itoh et al., 1988) and rat (Yanagisawa et al.2, 1988) preproendothelins were also cloned and sequenced. Originally, the differences among them were thought to be due to species variation until 1989 when Inoue et al. made a distinction among three isopeptides encoded by different genes in the mammalian genome but all with 'endothelin-like' sequences. The original endothelial derived porcine endothelin and the human endothelin were named "endothelin-1". The rat endothelin was named "endothelin-3" and a human endothelin-3 was later cloned (Bloch et al., 1989). The third endothelin gene sequence discovered by this group was named "endothelin-2".

Endothelin-1, endothelin-2 and/or endothelin-3 found in humans, pigs, rats and later in mice and dogs share the same disulfide bonding. Although all of them are 21residue peptides, they differ from each other in amino acid composition (reviewed by Phillips et al., 1992). For example, endothelin-1 has the same amino acid sequence in all five species mentioned before. Mouse and human endothelin- 2 differ by only one amino acid but differ from endothelin-1 by three and two amino acids respectively. Endothelin3 from rats and humans have identical amino acid sequences but differ from endothelin-1 by six amino acids (Phillips et al., 1992). 
Numerous studies identified two subtypes of receptors for the three types of endothelin. Endothelin receptor A (EdnrA) was found to have high affinity for endothelin-1 and endothelin-2 but not endothelin-3, whereas endothelin receptor B (EdnrB) can bind all three types of endothelin (Takayanagi et al., 1991). EdnrB and EdnrA were further characterized as G-coupled seven transmembrane receptors (Hosoda et al., 1994).

Despite the fact that all three types of endothelin act as vasoconstrictors, it has been established that they have different functions during embryonic development. For instance, signaling of Edn-1 through EdnrA plays an important role in the development of cardiac neural crest cells. Embryos deficient for both EdnrA and Edn-1 display defects in craniofacial structures, great vessels, and cardiac outflow tract (Clouthier et al., 1998; Kurihara et al., 1994). Also, it has been found that the Edn-1/EdnrA signaling pathway plays an essential role in aortic patterning by affecting postmigratory cardiac neural crest cell development (Yanagisawa et al., 1998).

Similarly to the Edn-1/EdnrA signaling pathway, the Edn-3/EdnrB signaling pathway has been found to be indispensable for the proper embryonic development of neural crest derivatives such as, melanocytes and enteric neurons. As mentioned before, mutations in mouse $E d n 3$ and $E d n r B$ result in the lethal spotting $(l s)$ and piebald lethal $(s l)$ phenotypes, respectively, both of which exhibit lack of enteric ganglia and abnormal pigmentation. Since the development of these cell types is affected by the disruption of the Edn3/EdnrB signaling pathway, the specific stages in development in which it is necessary as well as its mode of action, at a cellular level and at a molecular level, are still a matter of investigation. 
Analysis of the temporal and spatial pattern of $E d n 3$ and $E d n r B$ in mouse embryos have shown that $E d n 3$ is expressed in distal and proximal gut mesenchyme throughout embryonic days 10-14 (10-14dpc) with stronger expression in the caecum (10-12dpc) at about the same time that $E d n r B$ expressing neural crest cells arrive at the site (Leibl, et al., 1999). Studies on $E d n r B$ expression on avian neural crest have shown that it is expressed by cells of the neuroepithelium just as the neural tube begins to fold at the level of the mesencephalon. It was also noted that $E d n r B$ expression was especially intense in the neural folds that later yield neural crest cells, depending on the rostrocaudal level considered (Nataf et al., 1996). Later in development $E d n r B$ positive cells were found in dorsal root ganglia (DRG) and sympathetic ganglia (SG) at the trunk level, in cranial nerves and associated sensory ganglia at the cephalic level, in Schwann cells lining the peripheral nerves and in the adrenal medulla up to E8 in quail (Nataf et al., 1996). $E d n r B$ was also found to be expressed by vagal neural crest cells during their migration and after they formed the Auerbach's and Meissner's plexuses of the gut wall and in the post-umbilical gut caudal to the ileocaecal junction from E6 onward (Nataf et al., 1996) during the colonization of the gut as described previously (Le Douarin and Teillet, 1973). The expression pattern of $E d n r B$ in mouse embryos is similar to that of avian embryos (Southard-Smith et al., 1998) but a detailed temporal analysis is missing.

Since EdnrB and Edn3 are expressed from E8 onwards, the phenotypes observed in the $\mathrm{EdnrB} / \mathrm{Edn} 3$ mutants could be due to the disruption of their signaling pathway at any of the stages of melanocyte and enteric development. Therefore, the EdnrB/Edn3 signaling pathway may be affecting neural crest precursors as they start migrating, after their lineages have segregated or after they have reached their final targets. Early studies 
on piebald mice conducted by Mayer (1965) in which he grafted embryonic neural tube and skin of piebald and wild type mouse embryos to White Leghorn chick embryos, demonstrated that melanoblasts differentiate only in the tissue environment of hair follicles. He proposed that the 'piebald gene' (now identified as mutant $E d n r B$ ) renders melanoblasts more sensitive to different levels of melanogenic stimuli and, therefore, piebald melanoblasts would not be able to differentiate unless they find themselves in an environment of high melanocytic activity such as the hair follicle. In order to support this hypothesis, Mayer (1967) conducted a second experiment to test if the lack of pigment observed in piebald mice was a result of a failure in migration or as he had proposed before, due to a failure in melanoblast differentiation. Using the same technique, he grafted $9 \mathrm{dpc}$ neural tube and $11 \mathrm{dpc}$ skin explants from wild type and piebald mouse embryos into combination to chick emryos. After 15 days of incubation he examined pigment production and migration of neural tube cells using tritiated thymidine and autoradiography. Grafts of wild-type neural tubes and wild-type skin produced pigmented hair whereas grafts of piebald neural tubes and piebald skin produced pigment free hair. However, the pattern of migration of labeled wild type melanoblasts was identical to that of piebald melanoblasts which favors Mayer's hypothesis that the coat spotting present in piebald mice is due to a failure of melanoblasts differentiation in certain tissue environments, not a failure in their migration.

In a more recent study conducted by Pavan and Tilghman (1994), melanocyte development in piebald lethal embryos was examined using tyrosine related protein-2 (Trp-2) as an early maker for melanoblasts. They found that the number of Trp- $2^{+}$cells was significantly lower in piebald embryos at $10.5 \mathrm{dpc}$ than in wild type embryos 
suggesting that this difference in number represents the earliest indication of the piebald gene's activity and that the wild type gene $(E d n r B)$ must act very early in melanocyte development, before or at the same time as neural crest migration.

After the lethal spotting and the piebald lethal loci were identified ( $E d n 3$ and $E d n r B$, respectively), numerous transgenic studies were directed to find out the time of action of the genes involved in the development of the cell types affected (melanocytes and enteric neurons). Transgenic studies using the human dopamine- $\beta$-hydroxylase (D $\beta H)$ promoter ${ }^{1}$ to direct expression of $E d n r B$ in spotting lethal $(s l / s l)$ rats demonstrated that $\mathrm{EdnrB}$ is necessary for the development of enteric neurons at a different time than it is for melanocytes. In this study, researchers were able to prevent aganglionosis but were not able to prevent color coat spotting suggesting that the time of action of EdnrB on enteric neurons happens after melanocytes have diverged from their common precursor (Gariepy et al., 1998). In contrast with the previous study, a different group had the $E d n r B$ locus under the control of tetracycline-dependant transactivators, tTA or rtTA in mice (Shin et al., 1999). This group was able to pin-point a specific time period during which EdnrB expression is necessary for the regular development of both, melanoblasts and enteric neurons. They found $E d n r B$ expression is required between $10 \mathrm{dpc}$ and $12.5 \mathrm{dpc}$ for the development of enteric neurons and melanoblasts, which coincides with the time when they begin migrating from the MSA (migrating stage area) ${ }^{2}$. To further support Shin's conclusion, another group used a dopamine- $\beta$-hydroxylase (D $\beta H)$

\footnotetext{
${ }^{1} \mathrm{D} \mathrm{H}$ activity begins at $9.5 \mathrm{dpc}$, continues throughout gut colonization and persists postnatally in a subset of enteric neurons.

${ }^{2}$ The MSA (migrating stage area) is an area lateral to the neural tube where neural crest derived melanoblasts presumably remain for 24 hours before they begin their migration (10dpc) (Shin et al., 1999).
} 
promoter to control the expression of $E d n 3$ and $\operatorname{Ret}$ (receptor tyrosine kinase), which has also been identified as necessary for the development of enteric neural crest lineage together with its ligand gdnf (glial-cell derived neurotrophic factor). When they used homozygous lethal spotting $(l s / l s)$ mouse embryos to determine if the transgene would compensate for the Edn3 defficiency, they found that the D $\beta H$-Edn 3 transgene was able to prevent aganglionosis and piebaldism showing that the timing is the same for both lineages, whereas D $\beta H-$ Ret was not. They also found that Edn3 signaling is necessary for enteric neuroblasts once they reach the gut and as they begin colonization, implying that Edn3 might prevent precursor cells from differentiating until they reach their target position (Rice et al., 2000).

Since $E d n 3$ expression was localized to the environment surrounding NCCs (Nataf et al., 1998), many studies were devoted to investigating what the effects of Edn3 would be in vitro, especially on melanocytes and enteric neurons, the two cell types affected by mutations in $E d n 3$ and $E d n r B$. Lahav et al. (1996), found that Edn3 acts as a proliferating agent of avian NCCs, greatly increasing the number of melanocytes in primary neural crest cultures. Similar results were obtained for mouse neural crest cultures which showed that Edn3 induces the proliferation and aids in the survival of melanocyte progenitors in conjunction with the signaling of steel factor through the $c$-kit receptor (Reid et al., 1996). Their study also pointed out that Edn3 (but not Edn1) induces neural crest cells pigmentation suggesting that Edn 3 plays a role in the final differentiation of melanocytes. However, studies by Stone et al. (1997) using clonal analysis, concluded that although there was an increase in the number of neural crest cells, these were not only melanoblasts and melanocytes but also multipotent precursors 
yielding more than one cell type. Their results suggest that Edn3 acts on two types of precursors: those giving rise to melanocytes, adrenergic cells and sensory-like cells, and those giving rise to melanocytes and Schwann cells. Their results also suggest that Edn3 inhibits the final differentiation of precursor cells and prevents their loss of developmental potential. This suggests that, in the case of melanoblasts, it keeps them undifferentiated until they reach their final destination. Furthermore, a study conducted by Opdecamp et al. (1998) revealed that melanoblasts did not differentiate or proliferate unless subjected to treatment with any of the three types of endothelin. Once endothelins were added to neural crest cultures the number of melanoblasts and melanocytes increased significantly. This was consistent with an early finding that endothelins acted on signal transduction and proliferation in human melanocytes based on the observation that DNA synthesis as well as melanin synthesis (characteristics of a proliferative agent) were stimulated by endothelins (Yada et al., 1991). Not only has Edn3 been shown to increase the number of melanocytes, it has also been found to induce the reversion of melanocytes to glia via a glia-melanocyte progenitor (Dupin et al., 2000). Nevertheless, Wu et al. (1999) used crest derived fetal gut cells and demonstrated that Edn3 did not have the same effect on mammalian precursors of enteric neurons. It actually decreased the number of $\mathrm{NC}$ derived neurons and induced the development of enteric smooth muscle. They proposed that Edn3 prevents immature differentiation of precursors until they colonize the gut, an idea previously described by Stone et al. (1997). 


\section{The question.}

Although there is overwhelming data indicating that many neural crest derivatives depend upon Edn3 signaling through EdnrB, there is little information on what happens downstream of this pathway.

As mentioned before, EdnrB and EdnrA have been identified as seventransmembrane G-coupled receptors. Early studies on signal transduction in fibroblasts found that Edn1 stimulated proliferation through transduction associated with inositol phosphate (Kusuhara et al., 1989). Subsequent studies on human melanocytes found that levels of inositol triphosphate $\left(\mathrm{IP}_{3}\right)$ and intracellular calcium were substantially increased after the addition of Edn1, Edn2 and Edn3 to melanocytes cultures. In addition, endothelins stimulated DNA and melanin synthesis as well as increase proliferation of melanocytes (Yada et al., 1991). Later studies demonstrated that EdnrB binds all three endothelins and is coupled to heterotrimeric G proteins (Aramori and Nakanishi, 1992; Takagi et al., 1995). Vichi et al. (1999) showed that the seventh transmembrane domain (TMD7) of EdnrB regulates the AP-1 ${ }^{3}$ (active gene regulation protein) transcriptional

\footnotetext{
${ }^{3}$ Some G coupled receptors, such as EdnrB, activate phopho-inositide specific phopholipase C. This enzyme cleaves $\mathrm{PIP}_{2}$ (phosphatidylinositol biphosphate) to generate $\mathrm{IP}_{3}$ (inositol triphosphate) and DAG (diacylglycerol). $\mathrm{IP}_{3}$ leaves the plasma membrane and binds to $\mathrm{Ca}^{2+}$ channels in the endoplasmic reticulum (ER) which triggers the release of $\mathrm{Ca}^{2+}$ into the cytosol. The biological significance of $\mathrm{Ca}^{2+}$ release is still unclear. On the other hand, DAG can be further cleaved to arachidonic acid which can act as a messenger or be used in the synthesis of eicosanoids. But most importantly, DAG activates a crucial serine/threonine protein kinase, $\mathrm{pkC}$, which phosphorylates selected proteins in the cell. The initial rise in cytosolic $\mathrm{Ca}^{2+}$ causes $\mathrm{pkC}$ to translocate from the cytosol to the cytoplasmic side of the plasma membrane where it is activated by $\mathrm{DAG}, \mathrm{Ca}^{2+}$ and phospholipid phophatidylserine. $\mathrm{PkC}$ then goes on to regulate transcription in either of two ways: it can activate an inhibitor protein which releases a gene regulatory protein or it can activate other kinases such as a MAP kinase which in turn activates regulatory gene proteins. One important member of MAP kinase transcriptional activation is the complex formed by Elk-1 and serum response factor (SRF) which is bound to the regulatory region of the fos gene. Activation of this complex leads to transcription of fos. Alternatively, MAP kinases can activate Jun proteins which combine with the newly made Fos protein to form the active gene regulatory protein called AP-1. AP-1 turns on additional genes, although its role in cell proliferation is still unclear (Alberts et al., 1994).
} 
pathway and that the cytoplasmic tail of the receptor is involved in selective $\mathrm{G}_{q}$ coupling. ${ }^{4}$ It has also been found that the third intracellular loop of EdnrB is important for $\mathrm{G}_{\mathrm{i}}$ coupling involved in the inhibition of the cyclic AMP pathway, and that it does not interfere with $\mathrm{G}_{\mathrm{q}}$ coupling (Auricchio et al., 1999). More recent studies found that optimal signal transduction through EdnrB depends on $G_{q}$ coupling rather than on $G_{0}$ or $\mathrm{G}_{i}$ coupling (Imamura et al., 2000). However, the most recent study on EdnrB signal transduction showed that $\mathrm{G}_{\mathrm{i}}$ coupling and therefore, cAMP activity, might also be important for intracellular signaling leading to neural crest cell derived neuron and glial differentiation (Fuchs et al., 2001).

In spite of all this information on EdnrB signal transduction, no research has been conducted to identify downstream targets of EdnrB mediated signaling of Edn3.

Consequently, this study has been concentrated on identifying such transcriptionally regulated targets which follow Edn3/EdnrB signaling.

\section{Preliminary data: Differential Display}

Differential Display (DD) RT-PCR was the method chosen to identify genes that are transcriptionally modified downstream of the Edn3/EdnrB signaling pathway. Primary neural tube cultures from $9.5 \mathrm{dpc}$ mouse embryos were established. Sixty-one cultures were induced with Edn3 and eighty-four cultures were not induced. Both sets of cultures were incubated at $37^{\circ} \mathrm{C}$ for a two-day period after which RNA was extracted. Approximately 855ng of RNA were obtained from the non-induced cultures and

\footnotetext{
${ }^{4}$ The major signaling pathway after EdnrB activation follows $\mathrm{G}_{\mathrm{q}}$ couplin , increase in intracellular $\mathrm{Ca}^{2+}$ concentrations and activation of a Jun N-terminal kinase (JNK). The minor signaling pathway involves
} 
888.75ng were obtained from cultures induced with Edn3. The extracted RNA was subjected to RT-PCR using anchoring primers specially designed to bind to the poly-A tail of mRNA and the immediate nucleotide upstream of the poly-A tail. These primers were labeled $H-T_{11} G, H-T_{11} A$ and $H-T_{11} C$. Each one of them contains 11 T's (complementary to the poly-A tail) and an anchoring $\mathrm{G}, \mathrm{A}$, or $\mathrm{C}$ designed to bind a $\mathrm{C}, \mathrm{T}$, or G, respectively, that might be found immediately upstream the poly-A tail.

The cDNA obtained from RT-PCR was then amplified using the same anchoring primers used for the previous reaction together with arbitrary primers designed to bind consensus promoter sequences. The eight arbitrary primers used were labeled $\mathrm{AP}_{1}$ through $\mathrm{AP}_{8}$. Both sets of primers were part of a Differential Display kit obtained from GenHunter.

The products of this amplification were run in a $6 \%$ polyacrylamide gel creating a characteristic 'fingerprint' of the initial mRNA. Products from induced and non-induced cultures were loaded in contiguous lanes (induced: right, non-induced:left) to facilitate the identification of differentially expressed bands. If a band in the 'induced' lane appears darker or lighter than in the 'non-induced' lane it denoted upregulation or downregulation after induction of Edn3, respectively. A picture of the Differential Display Gel is shown in Figure 2. Forty-eight differentially expressed bands were selected for analyses. Thirty bands of the forty-eight selected were analyzed in this study. Glycerol stocks of clones containing bands $25,28,38,39$ and 48 had been established prior to the beginning of this project, but were also analyzed and included in this investigation.

activation of $\mathrm{G}_{a \mathrm{i}}$ which inhibits adenylate cyclase (Fuchs et al., 2001). 


\section{METHODOLOGY.}

\section{Re-amplification.}

To avoid any artifacts and to confirm the amplification of differentially expressed bands, 25 bands were subjected to re-amplification. Bands 4, 6, 9, 17, 18, 21, 26, 27, 29, 30, 31, $32,33,34,35,35,36,37,40,41,42,43,44,45,46$, and 47 were re-amplified using the same anchoring primers used for DD-RT PCR obtained from GenHunter.

The primers used for re-amplification of these 25 bands were:

- Arbitrary primers: $\mathrm{AP}_{1}, \mathrm{AP}_{2}, \mathrm{AP}_{3}, \mathrm{AP}_{4}, \mathrm{AP}_{5}, \mathrm{AP}_{6}$, and $\mathrm{AP}_{8}$

- Anchoring primer: $\mathrm{H}-\mathrm{T}_{11} \mathrm{C}$

The same anchoring primer, $\mathrm{H}-\mathrm{T} 11 \mathrm{C}$, was used for all re-amplification reactions. $\mathrm{AP}_{1}$ was used to amplify bands $4,9,29,30$, and $31 . \mathrm{AP}_{2}$ was used to amplify bands 6,32 , and 33. $\mathrm{AP}_{3}$ was used to amplify bands $34,35,36$, and $37 . \mathrm{AP}_{4}$ was used to amplify band 40 . $\mathrm{AP}_{5}$ was used to amplify bands $41,42,43,44$, and $45 . \mathrm{AP}_{6}$ was used to amplify bands $17,18,21,46$, and $47 . \mathrm{AP}_{8}$ was used to amplify bands 26 and 28.

All PCR reactions underwent the same thermocycle: (1) $94^{\circ} \mathrm{C}$ x $5^{\prime}$ (2) $94^{\circ} \mathrm{C}$ x $30^{\prime \prime}$ (3) $40^{\circ} \mathrm{C} \times 2^{\prime}$ (4) $72^{\circ} \mathrm{C} \times 1^{\prime}$ (5) Go to $2 \times 40$ (6) $72^{\circ} \mathrm{C} \times 5^{\prime}$ (7) $4^{\circ} \mathrm{C}$ forever. All PCR products were run in a $1 \%$ agarose gel to check for re-amplification. Only eleven bands were successfully re-amplified.

\section{Preparation of clones.}

Bands that were re-amplified were excised from the agarose gel and Gel Purified (Qvick) according to the manufacturer's protocol. They were subsequently cloned into the $\mathrm{pCR}$ Il cloning vector (Invitrogen) following manufacturer's instructions. Transformed cells 


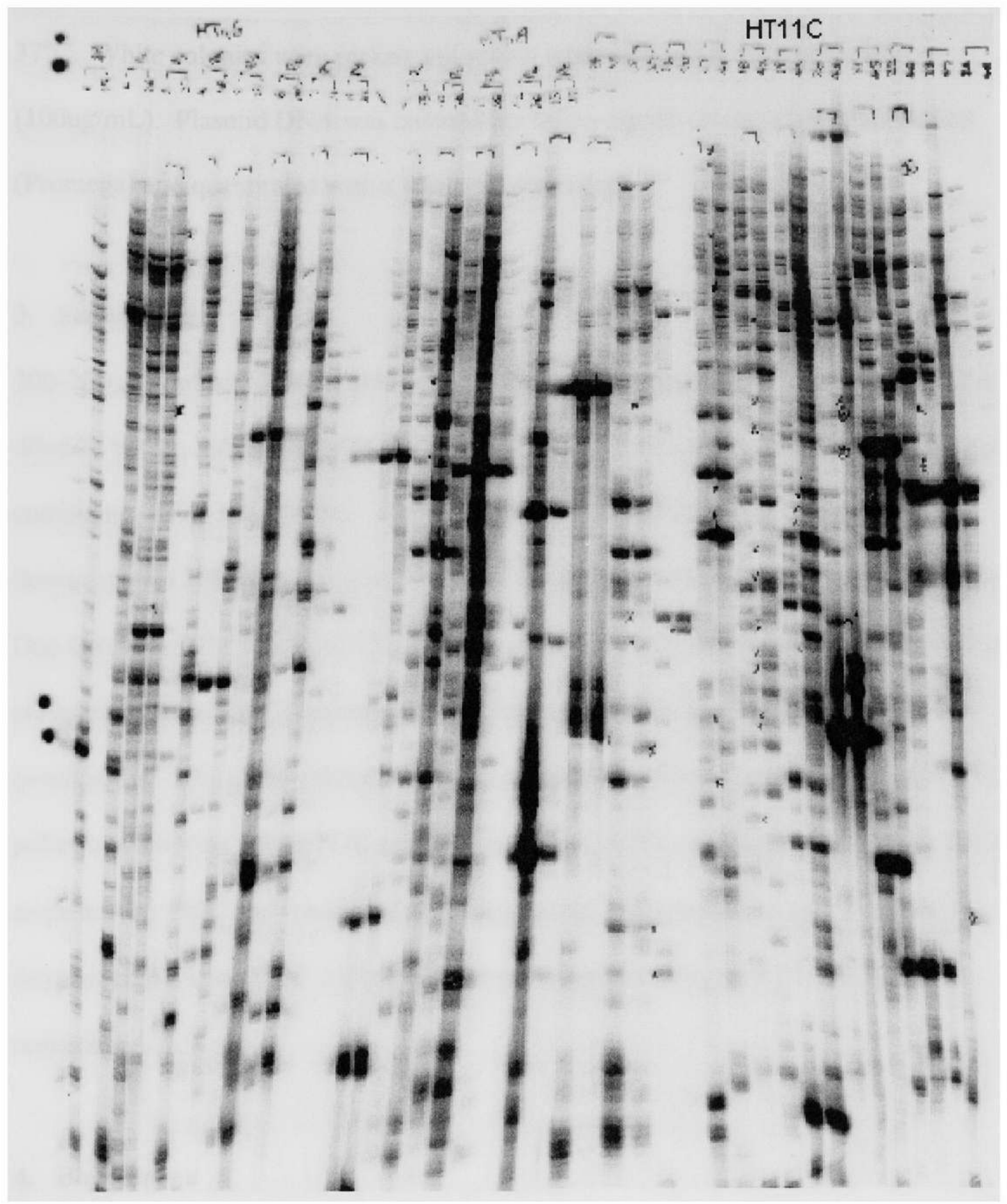

Figure 2. Differential Display RT-PCR Gel. The arbitrary primers (labeled $\mathrm{P}_{1-}$ 8) and the oligo-dT primers ( $\mathrm{HT}_{11} \mathrm{G}, \mathrm{HT}_{11} \mathrm{~A}$ and $\mathrm{HT}_{11} \mathrm{C}$ ) used for each lane are shown at the top of the gel. Each pair of lanes contains cDNA obtained from Edn-3 induced cultures (right lane) and non-induced cultures (left lane). Bands that showed upregulation after induction with Edn-3 are darker in the 'induced' lane whereas bands showing downregulation are lighter in the 'induced' lane. Forty-eight bands that clearly displayed this difference were selected for analysis. 
were plated on LB plates containing X-gal and ampicillin and left to grow overnight at $37^{\circ} \mathrm{C}$. White colonies were picked and grown overnight in LB with ampicillin (100ug/mL). Plasmid DNA was isolated the following day using a SV Miniprep kit (Promega) and quantitated with a spectrophotometer.

\section{Sequencing.}

200-700ng of plasmid DNA were used for each sequencing reaction together with $3 \mathrm{ul}$ dilution buffer, $2 \mathrm{ul}$ primer M13 (F or R), $2 \mathrm{ul} \mathrm{Big} \mathrm{Dye} \mathrm{terminator} \mathrm{and} \mathrm{UV-treated} \mathrm{dH}_{2} \mathrm{O}$ to complete a $20 \mathrm{ul}$ total volume. These samples were then subjected to the following

thermocycle: (1) $96^{\circ} \mathrm{C} \times 30^{\prime \prime}(2) 50^{\circ} \mathrm{C} \times 30^{\prime \prime}(3) 60^{\circ} \mathrm{C} \times 3^{\prime}$ (4) Go to $1 \times 29$ (5) $4^{\circ} \mathrm{C}$ forever. One volume of $7 \mathrm{M} \mathrm{NH}_{4} \mathrm{OAC}(10 \mathrm{ul})$ and 3 volumes of ETOH $(90 \mathrm{ul})$ were added to each reaction, covered with aluminum foil to protect from light and left to precipitate overnight at $-20^{\circ} \mathrm{C}$. The precipitate was centrifuged at $14000 \mathrm{rpm}$ for $30 \mathrm{~min}$ at $4^{\circ} \mathrm{C}$, the pellet washed with $70 \% \mathrm{ETOH}$ and then air-dried. At this point the samples can be kept as pellets at $-20^{\circ} \mathrm{C}$ and when ready for sequencing, resuspended in $3 \mathrm{ul}$ of deionized formamide:dextran (5:1). All samples were sequenced using an ABI 377 automatic sequencer.

\section{Blasting.}

The sequences obtained from the ABI 377 were edited to delete the pCR II plasmid sequence. The sequence of the inserts was then submitted to GenBank (www.ncbi.nlm.nih.gov/Database/index.html) for a homology search (BLAST). The inserts were blasted against a nucleotide database, a protein database as well as against an 
EST (Expressed Sequence Tags) database. Inserts corresponding to bands 28,39 and 40 were selected for further characterization because to of their high homology to SPC12 and WSB1.

\section{Semi-quantitative RT-PCR.}

cDNAs from Edn3-induced cultures and from non-induced cultures were subjected to semi-quantitative PCR to compare the amount of WSB1 (band no. 39) and SPC12 (band no. 28) present in both of them. Primers were designed to target a fragment of this sequence and for HPRTg, a housekeeping gene used as a control. All primers were designed using Primer 3 software from The Whitehead Institute for Genomic Research (www-genome.wi.mit.edu) and then ordered from Res Gen (Invitrogen - Life Technologies). The primers ordered for semiquantitative PCR were:

- WSB1-R: 5'-TGAATGGGCCCTTTAGTTTTCTC-3' and WSB1-L: 5'CCCATGGTCTTAAAATAATTGTCCC-3' which yield a 458 bp product size that is part of the 2463 bp cDNA sequence of WSB-1 (accession number: NM019653), starting at position 1819 and ending at position 2276 . The scale of synthesis was 50n mol. The PCR cycle used was: (1) $94^{\circ} \mathrm{C}$ x $5^{\prime}$ (2) $94^{\circ} \mathrm{C} \mathrm{x} 1^{\prime}$ (3) $58^{\circ} \mathrm{C} \mathrm{x} 1^{\prime}$ (4) $72^{\circ} \mathrm{C} \mathrm{x}$

1' (5) Go to $2 \times 44(6) 72^{\circ} \mathrm{C} \times 10^{\prime}$ (7) $4^{\circ} \mathrm{C}$ forever.

- SPC12-L: 5'-CAAGGGGCAGAAACTAGCTG-3' and SPC12-R: 5'-

CACACGGGAAAGAAGCATTG-3' which yield a 510 bp product size that is part of the $703 \mathrm{bp}$ full cDNA sequence obtained from the pancreas of a 10 day old mouse (accession number: AK007336). The starting position was 166 and ending at base 675. The scale of synthesis was $50 \mathrm{nmol}$. The PCR cycle for the amplification of this 
fragment was: (1) $94^{\circ} \mathrm{C} \times 5^{\prime}$ (2) $94^{\circ} \mathrm{C} \times 1^{\prime}$ (3) $55^{\circ} \mathrm{C} \times 1^{\prime}$ (4) $72^{\circ} \mathrm{C} \times 1^{\prime}$ (5) Go to $2 \times 44$

(6) $72^{\circ} \mathrm{C} \times 10^{\prime}$ (7) $4^{\circ} \mathrm{C}$ forever.

- HPRTg-L: 5'-AGGACTGAAAGACTTGCTCGA-3' and HPRTg-R: 5'-

GTAGCTCTTCAGTCTGATAAA-3' which yield a 200bp product size that is part of HPRTg, a housekeeping gene. The scale of synthesis was 50n mol. The PCR cycle for the amplification of this fragment was: (1) $94^{\circ} \mathrm{C} \times 5^{\prime}$ (2) $94^{\circ} \mathrm{C} \times 1^{\prime}$ (3) $58^{\circ} \mathrm{C} \times 1$ ' (4) $72^{\circ} \mathrm{C} \times 1^{\prime}$ (5) Go to $2 \times 44(6) 72^{\circ} \mathrm{C} \times 10^{\prime}(7) 4^{\circ} \mathrm{C}$ forever.

Primers were resuspended to a concentration of $100 \mathrm{mM}$ in UV-treated $\mathrm{H}_{2} \mathrm{O}$. 10ul of this solution was used to prepare a $10 \mathrm{mM}$ working stock. All primers were stored at $-20^{\circ} \mathrm{C}$.

\section{Image clones.}

For in-situ hybridization experiments, 1 or 2 ESTs (obtained from embryonic stages of development) homologous to the three genes to be characterized (SPC12, WSB1 and ubiquitinol cytochrome $\mathrm{c}$ reductase) were selected to be used as probes. For comparison purposes, another member of the SOCS (suppressor of cytokine signaling) family of genes (of which WSB1 is a member) was examined and an EST selected for it. Image Clones containing these ESTs in mammalian vectors with sites for SP6, T7 and/or T3 polymerases were purchased from ResGen-Invitrogen Corporation. These are the image clones purchased:

- Image clone \# 4016049: contained WSB1-EST (Accession Number: BF140245) inserted into pCMV-Sport6 cloning vector.

- Image clone\# 3601047: contained WSB2-EST (Accession Number: BE382004) inserted into pCMV-Sport6 cloning vector. 
- Image clone\# 1382191: contained 40a-EST (accession number: AI462067) inserted into $\mathrm{pT} 3 \mathrm{~T} 7 \mathrm{~d}$ cloning vector.

- Image clone\# 389242: contained 28-EST (accession number: W74994) inserted into pT3T7d cloning vector.

- Image clone\# 3025933: contained WSB1-EST (2) (accession number: AW744360) inserted into $\mathrm{pT} 3 \mathrm{~T} 7 \mathrm{~d}$ cloning vector.

All image clones were provided as cultures in LB media with 8\%glycerol. The cultures were streaked on LB plates containing ampicillin and grown at $37^{\circ} \mathrm{C}$ overnight. The image clones were stored at $-80^{\circ} \mathrm{C}$. The following day, twelve colonies were picked and plated again on a new LB plate with ampicillin and grown at $37^{\circ} \mathrm{C}$ overnight. The streaked plates were wrapped in parafilm and stored at $4^{\circ} \mathrm{C}$. To determine which of the 12 colonies contained the insert, I performed 'colony-PCR'. A Master Mix for each image clone was prepared containing 222.6ul UV-treated and filtered dH2O, 28ul 10X buffer, 5.6ul dNTPs, 5.6ul primer \#1, 5.6ul primer \#2, and 5.6ul Taq polymerase. The mix was then aliquoted into 13 tubes containing 19.5 ul of the mix (12 for each colony and 1 as control). The 12 colonies were picked and used to inoculate each of the reactions. The samples were then subjected to their correspondent PCR cycle depending on the set of primers used:

- Image clone \# 4016049: WSB1-EST-L: 5'-GGATCAGCTACTCCTGCCAC-3' and WSB1-EST-R: 5'-ACTCGCCTTGGTAGTGTGCT-3' which yield an 886 bp product from the WSB1-EST cDNA (AN: BF140245) selected from the blasting results, starting at position 16 through 901. The PCR cycle used for colony PCR was: (1) 
$94^{\circ} \mathrm{C} \times 10^{\prime}$ (2) $94^{\circ} \mathrm{Cx}^{\prime}$ ' (3) $55^{\circ} \mathrm{C} \times 1^{\prime}$ (4) $72^{\circ} \mathrm{C} \times 1^{\prime}$ (5) Go to $2 \times 30$ (6) $72^{\circ} \mathrm{C} \mathrm{x}$ $10^{\prime}(7) 4^{\circ} \mathrm{C}$ forever.

- Image clone\# 3601047: WSB2-EST-L: 5'-AAGGATTCGAAGCCAAGAGC-3' and WSB2-EST-R: 5'-CAAACACACGGGTGTCAAAC-3' which yield a 604 bp product from the WSB2-EST cDNA (AN: BE382004) selected from the blasting results, starting at position 68 through 671. The PCR cycle used for colony PCR was: (1) $94^{\circ} \mathrm{C} \times 10^{\prime}$ (2) $94^{\circ} \mathrm{C} \times 1^{\prime}$ (3) $55^{\circ} \mathrm{C} \times 1^{\prime}$ (4) $72^{\circ} \mathrm{C} \times 1^{\prime}$ (5) Go to $2 \times 30$ (6) $72^{\circ} \mathrm{C} \times$ $10^{\prime}(7) 4^{\circ} \mathrm{C}$ forever.

- Image clone\# 1382191: 40aEST-L: 5'-AGATGTGCATGCTAACAATGG-3' and 40aEST-R: 5'-TCTTCTGACATTACCTCACTGC-3' which yield a 313 bp product from the 40a-EST cDNA (AN: AI462067) selected from blasting results, starting at position 95 through 407. The PCR cycle used for colony PCR was: (1) $94^{\circ} \mathrm{C} \times 10^{\prime}$ (2) $94^{\circ} \mathrm{C} \times 1^{\prime}$ (3) $54^{\circ} \mathrm{C} \times 1^{\prime}$ (4) $72^{\circ} \mathrm{C} \times 1^{\prime}$ (5) Go to $2 \times 35$ (6) $72^{\circ} \mathrm{C} \times 10^{\prime}$ (7) $4^{\circ} \mathrm{C}$ forever.

- Image clone\# 389242: 28EST-L: 5' -CCCCGCAAACTTTACTCCTT-3' and 28ESTR: 5'-GGCGGTTTAAGCTCATGTTT-3' which yield a 465 bp product from the 28EST cDNA (AN: W74994) selected from blasting results, starting at position 13 through 477. The PCR cycle used for colony PCR was: (1) $94^{\circ} \mathrm{C} \times 10^{\prime}$ (2) $94^{\circ} \mathrm{C} \times 1$ ' (3) $54^{\circ} \mathrm{C} \times 1^{\prime}$ (4) $72^{\circ} \mathrm{C} \times 1^{\prime}$ (5) Go to $2 \times 35$ (6) $72^{\circ} \mathrm{C} \times 10^{\prime}$ (7) $4^{\circ} \mathrm{C}$ forever.

- Image clone\# 3025933: WSB1-EST (2)-L: 5'-AGGAAGCTGGAAGGTCATCA-3' and WSB1-EST(2)-R: 5'-GGCAGTCTTGGGACTTCTTG-3' which yield a 476 bp product from the WSB1-EST cDNA (AN: AW744360) selected from blasting results, starting at position 46 through 521. The PCR cycle used for colony PCR was: (1) 
$94^{\circ} \mathrm{C} \times 10^{\prime}(2) 94^{\circ} \mathrm{C} \times 1^{\prime}$ (3) $54^{\circ} \mathrm{C} \times 1^{\prime}$ (4) $72^{\circ} \mathrm{C} \times 1^{\prime}$ (5) Go to $2 \times 35(6) 72^{\circ} \mathrm{C} \times 10^{\prime}$

(7) $4^{\circ} \mathrm{C}$ forever.

Upon completion of PCR, the samples were run in a $1.5 \%$ agarose gel to check which of the 12 colonies contained the insert. If all colonies were positive for the insert, one of them was selected randomly to inoculate $\mathrm{LB}$ (with amp) and grow overnight at $37^{\circ} \mathrm{C}$. A glycerol stock was created for each clone and stored at $-80^{\circ} \mathrm{C}$.

\section{Isolation of Plasmid DNA.}

After growing the clones overnight, plasmid DNA containing the inserts was isolated using a SV Miniprep Kit (Promega) according to manufacturer's instructions. Plasmid concentration was then measured using a SmartSpec spectrophotometer (Biorad).

\section{In-situ hybridization.}

\section{Riboprobe synthesis.}

About 10ug of plasmid DNA was linearized with appropriate enzymes (EcoRI for pCMV-Sport6 and XhoI for pT3T7d cloning vector) for $1 \mathrm{hr}$ at $37^{\circ} \mathrm{C}$. The linearized plasmid template was incubated for another half an hour after the addition of 1 ul of proteinase $\mathrm{k}(10 \mathrm{mg} / \mathrm{ml})$. Two phenol extractions and one of chloroform followed, as well as ethanol precipitation overnight at $-20^{\circ} \mathrm{C}$. The following day, the samples were spun down at $14000 \mathrm{rpm}$ for 30 minutes at $4^{\circ} \mathrm{C}$ and resuspended in $10 \mathrm{ul}$ to a concentration of $1 \mathrm{ug} / \mathrm{ul}$. One microliter was run in a $1.5 \%$ agarose gel to check for complete linearization. The riboprobe synthesis reaction was set up as follows: lul linearized 
template ( $1 \mathrm{ug} / \mathrm{ml}), 2 \mathrm{ul} 10 \mathrm{X}$ transcription buffer, 2ul dig-labeled NTPs mix, 2ul RNA polymerase (T7, T3 or SP6), lul RNAse inhibitor and 12ul DEPC $\mathrm{H}_{2} \mathrm{O}$. The reaction was incubated at $37^{\circ} \mathrm{C}$ for $2 \mathrm{hrs}$ in a water bath. $2 \mathrm{ul}$ of $0.2 \mathrm{M}$ EDTA and $2.5 \mathrm{ul}$ of $4 \mathrm{M} \mathrm{LiCl}$ were added to stop the reaction and $75 \mathrm{ul} \mathrm{ETOH}$ to precipitate nucleic acids. The samples were centrifuged for 30 minutes at maximum speed $(14000 \mathrm{rpm})$ at $4^{\circ} \mathrm{C}$, pellet was washed with $70 \%$ ETOH in DEPC $\mathrm{H}_{2} \mathrm{O}$ and centrifuged again for 15 minutes under the same conditions. The pellet was finally resuspended in 20ul of DEPC $\mathrm{H}_{2} \mathrm{O}$ and one microliter was run in a $1.5 \%$ agarose gel to compare the amount of RNA synthesized to DNA left. All probes were stored at $-20^{\circ} \mathrm{C}$.

\section{Whole mount in-situ hybridization}

Embryos of ages $8.5 \mathrm{dpc}$ through $12.5 \mathrm{dpc}$ were dissected from $\mathrm{C} 57 \mathrm{BL} / 6 \mathrm{~J}$ pregnant mice, placed in $4 \mathrm{ml}$ glass vials and fixed in $4 \%$ paraformaldehyde overnight. They were then placed in $100 \%$ methanol and kept at $-20^{\circ} \mathrm{C}$. The whole mount in-situ hybridization protocol that I used is divided into four days:

Day1: Pretreatment and hybridization. Embryos were rehydrated through the following dilutions of $\mathrm{MeOH}$ in PBT (PBS+0.1\%Tween 20): $75 \%, 50 \%$ and $25 \% \mathrm{MeOH}$ in PBT for 5 minutes each and then washed with PBT twice. The embryos were then bleached with $6 \%$ hydrogen peroxide in PBT for 1 hour while rocking at room temperature. Their hindbrains were then punctured with the help of forceps and the embryos were subsequently permeabilized with $10 \mathrm{ug} / \mathrm{ml}$ proteinase $\mathrm{K}$ in PBT. Permeabilization times were as follows: $8.5 \mathrm{~d}: 15$ minutes; $9.5 \mathrm{~d}: 20$ minutes; $10.5 \mathrm{~d}: 25$ minutes; $11.5 \mathrm{~d}: 30$ minutes; $12.5 \mathrm{~d}$ : 35 minutes. The treatment was stopped with $2 \mathrm{mg} / \mathrm{ml}$ glycine in PBT for 
10 minutes at room temperature while rocking. The embryos were washed with PBT twice before post-fixing them with $4 \%$ paraformaldehyde, $0.2 \%$ gluteraldehyde in PBT for 20 minutes at room temperature while rocking, and washed again twice with PBT.

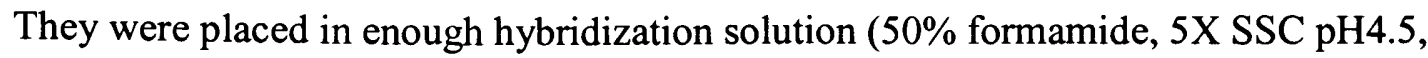
$50 \mathrm{ug} / \mathrm{ml}$ yeast $\mathrm{tRNA}, 1 \% \mathrm{SDS}, 50 \mathrm{ug} / \mathrm{ml}$ heparin) to cover them completely and were prehybridized for at least an hour at $70^{\circ} \mathrm{C}$. Embryos can be stored at this point at $-20^{\circ} \mathrm{C}$ for a long time. The hybridization solution was removed and new hybridization solution containing the probe (about $1 \mathrm{ug} / \mathrm{ml}$ ) was added. Embryos were hybridized overnight at $70^{\circ} \mathrm{C}$ in a water bath.

Day 2: Washing and Antibody addition. Embryos were washed with freshly made Solution 1 ( $50 \%$ formamide, $5 \mathrm{X} \mathrm{SSC} \mathrm{pH} 4.5,1 \%$ SDS) three times for 30 minutes each at $70^{\circ} \mathrm{C}$. They were then washed with also freshly made Solution $2(50 \%$ formamide, $2 \mathrm{X}$ $\mathrm{SSC} \mathrm{pH} 4.5$ ) three times for 30 minutes at $65^{\circ} \mathrm{C}$ and then washed another three times with TBST (TBS+0.1\% Tween 20) at room temperature for 5 minutes each. Embryos were blocked in $10 \%$ goat serum (heat inactivated at $56^{\circ} \mathrm{C}$ for 1 hour) in TBST for 2 hours at room temperature while rocking. Meanwhile, the anti-dig antibody was preabsorbed by adding a tiny amount of embryo powder ${ }^{5}$ to $0.5 \mathrm{ml}$ of TBST for each in-situ vial and heating at $70^{\circ} \mathrm{C}$ for 30 minutes, vortexing it and cooling in ice to finally add $5 \mathrm{ul}$ of goat serum and $1 \mathrm{ul}$ of anti-dig antibody. The antibody solution was then rocked at $4^{\circ} \mathrm{C}$ for 1 hour, pelleted and the supernatant was diluted with $1.5 \mathrm{ml}$ of $1 \%$ goat serum in TBST.

\footnotetext{
${ }^{3}$ Embryo powder was obtained from homogenizing 12.5-14.5 embryos in cold PBS, adding 4 volumes of cold acetone, mixing, and incubating on ice for 30 minutes. The mix was then centrifuged at $10000 \mathrm{~g}$ for 10 min after which the supernantant was removed, the pellet washed with cold acetone and spun again. The pellet was spread out and grounded with a mortar and a pestle into a fine powder on a sheet of filter paper. It was then air-dried and stored at $4^{\circ} \mathrm{C}$.
} 
The blocking solution was removed from the embryos and replaced with the diluted antibody solution. The embryos were left rocking overnight at $4^{\circ} \mathrm{C}$.

Day 3: Washing antibody. The embryos were washed 3 times with TBST at room temperature for 5 minutes each. They were then washed 5 times with TBST at room temperature for 1 hour or more each. Levamisole $(24 \mathrm{mg} / 50 \mathrm{ml})$ was added to the final wash and the embryos were left rocking overnight at $4^{\circ} \mathrm{C}$.

Day 4: Detection. Embryos were washed with NTMT (100mM NaCl, 100mM Tris pH 9.5, 50mM MgCl $2,0.1 \%$ Tween $20,2 \mathrm{mM}$ levamisole) 3 times at room temperature for 10 minutes each. NTMT was removed and replaced with substrate solution (45ul NBT and 35ul BCIP in 10ml NTMT). The vials were wrapped with aluminum foil to protect them from light and monitored every half and hour under a dissecting scope. When detection was complete they were washed in PBT twice and stored at $4^{\circ} \mathrm{C}$ in PBT. They were then photographed in PBT using 160T Ektachrome Kodak film.

\section{Cryosectioning.}

Following whole mount in-situ hybridization, embryos were post fixed in $4 \%$ paraformaldehyde at $4^{\circ} \mathrm{C}$ overnight while rocking. They were rocked in $10 \%$ sucrose at $4^{\circ} \mathrm{C}$ for 6 hours and left in $20 \%$ sucrose at $4^{\circ} \mathrm{C}$ overnight. The embryos were smeared with OCT twice to get rid of any sucrose, mounted in a plastic mold and frozen at $-80^{\circ} \mathrm{C}$ for about 5 minutes or until the OCT completely solidified. They were mounted head up on a mounting block by spreading some OCT, attaching the OCT block to it and letting it freeze inside the Cryostat (chamber temperature: $-20^{\circ} \mathrm{C}$ ). More OCT was poured around the block containing the embryo until it was firmly on the mounting block. All embryos 
were cross-sectioned at $30 \mathrm{um}$. All sections were placed on glass slides and kept on a slide warmer for 30 minutes. The slides were then mounted using water based mounting media and sealed with clear nail polish. Sections were examined using a compound microscope and some selected to be photographed using 160T Kodak film.

\section{RESULTS}

\section{Expression pattern of EdnrB.}

Since the previously mentioned expression studies of EdnrB have mostly been done on avian embryos, whole mount in-situ hybridization was performed on mouse embryos using EdnrB as a probe in order to confirm the expression seen in the chick. The digoxigenin-labeled riboprobes that were synthesized, hybridize to the complementary mRNA found in the embryo. An anti-dig antibody conjugated with alkaline phosphatase was used as part of the technique. Finally, development with alkaline phosphatase substrates yields color where hybridization has occurred. Consequently, areas that appeared to be dark purple in the embryos denoted hybridization of the probe to the complementary mRNA transcript.

At $11.5 \mathrm{dpc}, E d n r B$ expression was very strong in the ventricular zone of the brain and spinal cord as well as in various neural crest derivatives such as trigeminal ganglion, dorsal root ganglia, sympathetic ganglia, and the Schawnn cells lining of the peripheral nerves (Fig. 3A). 12.5 dpc embryos showed that $E d n r B$ continues to be expressed in the ventricular zone of the brain and spinal cord, in the dorsal root ganglia, sympathetic ganglia (and their projections) and in the trigeminal ganglion (Fig. 3B). Strong expression 
was also found in the heart and in the enteric neuron precursors colonizing the gut (Fig. 3B).
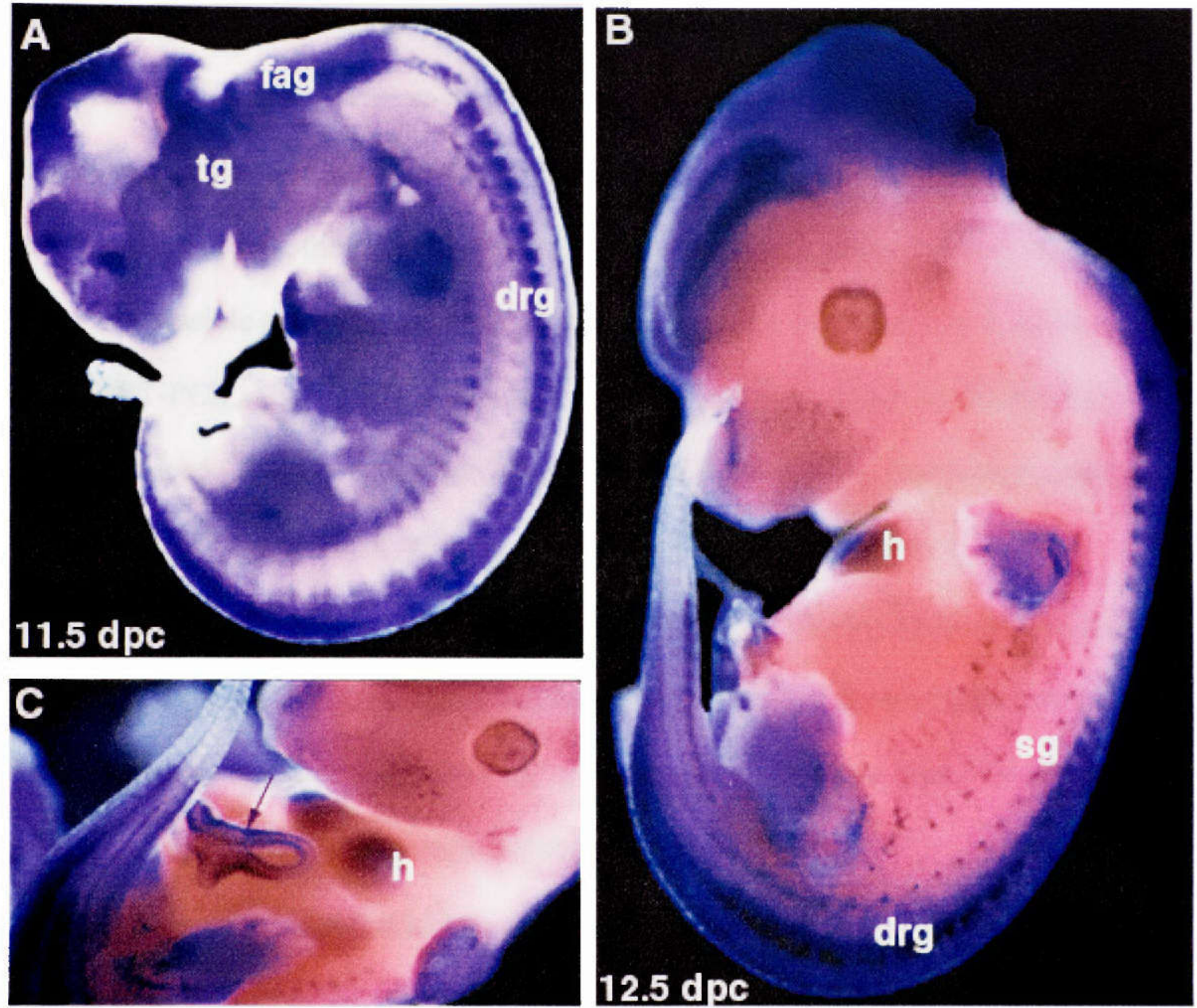

Figure 3. EdnrB expression pattern. Whole-mount in-situ hybridization of $11.5 \mathrm{dpc}$ (A) and $12.5 \mathrm{dpc}(\mathrm{B}, \mathrm{C})$ embryos. drg: dorsal root ganglia, fag: facio-acoustic ganglia, fb: forebrain, h: heart, sg: sympathetic ganglia, arrow: enteric ganglia. 


\section{Identification of differentially expressed bands after induction with Edn3.}

In order to confirm the amplification of the bands selected from the Differential Display Gel, they were re-amplified with the same primers used for their amplification prior to running the gel. Only 11 bands $(4,9,27,30,32,34,35,37,40,44)$ out of $25^{6}$ selected for the reaction were re-amplified and subsequently gel purified. The 11 fragments were cloned into the pCR-II cloning vector. Three clones from each cloning reaction were grown, the plasmid containing the insert was isolated and sequenced to check for possible amplification of more than one band by the primers and cycles used for DD RT-PCR. Clones that were previously obtained from bands 25,28 and 39 were also sequenced. All sequences were submitted to GenBank for a nucleotide homology search (BLAST). The results from the BLAST are presented in Table 1.

Since the fragments obtained from the Differential Display could belong to the untranslated region (UTR) of a gene sequence, sequences that showed high homology to uncharacterized cDNAs, were subjected to a secondary nucleotide blast. The results from the secondary BLAST are shown in Table 2.

cDNA sequences that had no significant homology to any known gene or gene family after the secondary blast were subjected to a translation BLAST to search for protein homology and conserved protein domains (GenBank translates the nucleotide sequence given and searches for homology against all translated sequences in the database). The results from the translation BLAST are shown in Table 3.

\footnotetext{
${ }^{6}$ The 25 bands subjected to re-amplification were: $4,6,9,17,18,21,26,27,29,30,31,32,33,34,35,36$, $37,40,41,42,43,44,45,46,47$.
} 


\begin{tabular}{|c|c|c|c|c|c|c|}
\hline $\begin{array}{l}\text { BAND } \\
\text { No. }\end{array}$ & CLONE & PRIMARY BLAST & SCORE & e VALUE & ACCESSION No & $\begin{array}{l}\text { UPREGULATED/ } \\
\text { DOWNREGULATED }\end{array}$ \\
\hline \multirow{3}{*}{4} & a & $\begin{array}{l}\text { mRNA ribosomal protein S6 (Rsp6) } \\
\text { 10/11d embryo cDNA } \\
\text { 11d embryo cDNA }\end{array}$ & $\begin{array}{l}204 \\
204 \\
204\end{array}$ & $\begin{array}{l}3 e-53 \\
3 e-53 \\
3 e-53\end{array}$ & $\begin{array}{l}\text { AK012284 } \\
\text { AK013333 } \\
\text { NM009096 }\end{array}$ & \multirow{3}{*}{ downregulated } \\
\hline & $\mathrm{b}$ & same as clone $4 \mathrm{a}$ & & & & \\
\hline & $\bar{c}$ & same as clone $4 a$ & & & & \\
\hline \multirow[t]{3}{*}{9} & a & $\begin{array}{l}\text { mRNA ribosomal protein S6 (Rsp6) } \\
\text { 11d embryo cDNA } \\
\text { 10/11d embryo cDNA }\end{array}$ & $\begin{array}{l}204 \\
204 \\
204\end{array}$ & $\begin{array}{l}2 \text { e-50 } \\
2 \text { e-50 } \\
2 \text { e-50 }\end{array}$ & $\begin{array}{l}\text { NM009096 } \\
\text { AK012284 } \\
\text { AK013333 }\end{array}$ & \multirow[t]{3}{*}{ downregulated } \\
\hline & $\mathrm{b}$ & same as clone $9 a$ & & & & \\
\hline & C & no homology & & & & \\
\hline \multirow[t]{4}{*}{24} & a & $\begin{array}{l}\text { Adult male tongue CDNA } \\
\text { Homo sapiens TATA box binding protein (TBP)-assoc. } \\
\text { factor, RNA polymerase II, G, 32kDa (TAF2G) }\end{array}$ & $\begin{array}{c}432 \\
96\end{array}$ & $\begin{array}{l}e-121 \\
7 \text { e-20 }\end{array}$ & $\begin{array}{l}\text { AK009322 } \\
\text { NM003187 }\end{array}$ & \multirow[t]{4}{*}{ downregulated } \\
\hline & & Human transcriptional activation factor TAFII32 mRNA & 96 & $7 \mathrm{e}-20$ & HSU21858 & \\
\hline & b & not available & & & & \\
\hline & c & not available & & & & \\
\hline \multirow{3}{*}{25} & a & no homology & & & & \multirow{3}{*}{ upregulated } \\
\hline & $\mathrm{b}$ & not available & & & & \\
\hline & c & not available & & & & \\
\hline \multirow{5}{*}{27} & & Similar to transmembrane 7 superfamily member 1 & 121 & $4 e-25$ & $\mathrm{BC} 003212$ & \multirow{5}{*}{ upregulated } \\
\hline & a & Transmembrane 7 superfamily member 1 (Tm7sf1) & 121 & 4 e-25 & NM031999 & \\
\hline & & Putative 7 pass transmembrane protein (Tm7sf1)mRNA & 121 & $4 \mathrm{e}-25$ & AF154337 & \\
\hline & $\mathrm{b}$ & same as $27 a$ & & & & \\
\hline & c & not available & & & & \\
\hline \multirow[t]{3}{*}{28} & $\bar{a}$ & $\begin{array}{l}\text { 10d old male pancreas cDNA } \\
\text { T-cell receptor alpha locus BAC clone }\end{array}$ & $\begin{array}{l}363 \\
137\end{array}$ & $\begin{array}{l}3 e-98 \\
3 e-30\end{array}$ & $\begin{array}{l}\text { AK007336 } \\
\text { AF259072 }\end{array}$ & \multirow{3}{*}{ upregulated } \\
\hline & $\bar{b}$ & not available & & & & \\
\hline & C & not available & & & & \\
\hline \multirow{3}{*}{30} & $\mathrm{a}$ & not able to edit sequence & & & & \multirow{3}{*}{ downregulated } \\
\hline & $\mathrm{b}$ & no homology & & & & \\
\hline & c & Human chr 16 BAC clone & & & $\mathrm{AC002044}$ & \\
\hline
\end{tabular}

Table 1. Primary nucleotide BLAST results. Continued on next page. 


\begin{tabular}{|c|c|c|c|c|c|c|}
\hline $\begin{array}{l}\text { BAND } \\
\text { No. }\end{array}$ & CLONE & PRIMARY BLAST & SCORE & e VALUE & ACCESSION No & $\begin{array}{c}\text { UPREGULATEDI } \\
\text { DOWNREGULATED }\end{array}$ \\
\hline \multirow{6}{*}{32} & 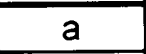 & Cctb gene for chaperonin containing TCP-1 beta subunit & 210 & $1 \mathrm{e}-54$ & $\mathrm{AB} 022156$ & \multirow{6}{*}{ downregulated } \\
\hline & & 94kb genomic sequence encoding Tsx gene & 198 & $2 e-48$ & MMTSXDNA & \\
\hline & & Endobrevin (Vamp8) gene-exon 1 & 196 & $9 e-48$ & AF247193 & \\
\hline & b & Non-receptor tyrosine kinase, Tyk2 gene & 196 & $9 e-48$ & AF052607 & \\
\hline & & GTF2IRD1 and CYLN2 genes & 194 & $4 e-47$ & AF289667 & \\
\hline & c & not able to edit sequence & & & & \\
\hline \multirow{3}{*}{34} & $\bar{a}$ & Embryonic stem cells cDNA & 89.7 & $3 e-15$ & AK010304 & \multirow{3}{*}{ downregulated } \\
\hline & $\mathrm{b}$ & not able to edit sequence & & & & \\
\hline & c & not available & & & & \\
\hline \multirow{6}{*}{35} & & $94 \mathrm{~kb}$ genomic sequence encoding Tsx gene & 204 & $3 e-50$ & MMTSXDNA & \multirow{6}{*}{ downregulated } \\
\hline & a & Endobrevin (Vamp8) gene-exon1 & 202 & $1 e-49$ & AF247193 & \\
\hline & & Non-receptor tyrosine kinase, Tyk2 gene & 202 & $1 e-49$ & AF052607 & \\
\hline & & GTF2IRD1 and CYLN2 genes & 200 & $5 e-49$ & AF289667 & \\
\hline & $\mathrm{b}$ & 18d embryo cDNA & 446 & $\mathrm{e}-123$ & AK003980 & \\
\hline & c & not able to edit sequence & & & & \\
\hline \multirow{3}{*}{39} & $a$ & 11d embryo cDNA & 341 & $2 e-91$ & AK019206 & \multirow{3}{*}{ downregulated } \\
\hline & $\mathrm{b}$ & not available & & & & \\
\hline & $\mathrm{c}$ & not available & & & & \\
\hline \multirow{5}{*}{40} & $\bar{a}$ & $\begin{array}{l}\text { 18d embryo cDNA } \\
\text { Adult male hippocampus cDNA }\end{array}$ & $\begin{array}{l}367 \\
361\end{array}$ & $\begin{array}{l}2 \text { e }-99 \\
1 \text { e-97 }\end{array}$ & $\begin{array}{l}\text { AK003443 } \\
\text { AK013513 }\end{array}$ & \multirow{5}{*}{ upregulated } \\
\hline & $\mathrm{b}$ & Myeloid ecotropic viral integration site-related gene Mrg1 & 305 & $8 \mathrm{e}-81$ & NM010825.1 & \\
\hline & & mRNA for homeodomain protein Meis2d & 305 & 8 e-81 & MMU57343 & \\
\hline & c & 18d embryo cDNA & 276 & $6 \mathrm{e}-72$ & AK003443 & \\
\hline & & Adult male hippocampus cDNA & 270 & 4 e-70 & AK013513 & \\
\hline \multirow{4}{*}{47} & $\bar{a}$ & Protein kinase inhibitor, gamma (Pkig) & 333 & $8 \mathrm{e}-89$ & MMU97170 & \multirow{4}{*}{ upregulated } \\
\hline & & Adenosine deaminase (ADA) gene & 333 & 8 e-89 & MMU73107 & \\
\hline & $\mathrm{b}$ & same as $47 a$ & & & & \\
\hline & c & not available & & & & \\
\hline
\end{tabular}

Table 1. Primary Nucleotide Blast. Description on next page. 
Table 1. Primary nucleotide BLAST results. The three clones from each band were denoted $\mathrm{a}, \mathrm{b}$ and $\mathrm{c}$. This table includes the known gene sequences and cDNA sequences obtained from homology searches. Score and e-values are also presented. A score is obtained from a local alignment without gaps of a pair of equal length segments, one from each of the two sequences being compared. A modification of the Smith-Waterman or Sellers algorithms finds all segment pairs whose scores can not be improved by extension or trimming. These are called high-scoring segment pairs or HSP scores. Because HSP scores tend to be higher if the alignments are longer, the e-value becomes necessary for statistical significance. The e-value is the probability of finding another homologous sequence with a higher score. Therefore, the smaller the e-value the more significant the results become. The accession number for GenBank of the known genes and cDNA sequences found are also shown. Sequences obtained from band 44 were did not give significant homology to any sequence in GenBank and therefore, were not included in this table. The actual sequences can be found in the Appendix. 


\begin{tabular}{|c|c|c|c|c|c|}
\hline $\begin{array}{l}\text { BANDI } \\
\text { CLONE }\end{array}$ & PRIMARY BLAST & SECONDARY BLAST & SCORE & $\begin{array}{c}\mathbf{e} \\
\text { VALUE }\end{array}$ & $\begin{array}{l}\text { ACCESSION } \\
\text { No. } \\
\end{array}$ \\
\hline $4 a$ & $\begin{array}{l}\text { 10/11d embryo cDNA (AK013333) } \\
\text { 11d embryo cDNA (AK012284) }\end{array}$ & Ribosomal protein S6 (Rps6), mRNA & 1584 & 0.0 & NM009096 \\
\hline $9 a$ & $\begin{array}{l}\text { 10/11d embryo cDNA (AK013333) } \\
\text { 11d embryo cDNA (AK012284) }\end{array}$ & Same as $4 a$ & 1584 & 0.0 & NM009096 \\
\hline $24 a$ & Adult male tongue cDNA (AK009322) & $\begin{array}{l}\text { Human transcriptional activation factor TAFII32 } \\
\text { mRNA } \\
\text { Rattus norvegicus neuronal cell death related gene }\end{array}$ & $\begin{array}{l}846 \\
309 \\
\end{array}$ & $\begin{array}{c}0.0 \\
6 \mathrm{e}-84 \\
\end{array}$ & $\begin{array}{l}\text { HSU21858 } \\
\text { RNU40188 } \\
\end{array}$ \\
\hline $28 a$ & 10d old male pancreas cDNA (AK007336) & Homo sapiens HSPC033, mRNA & 454 & $e-125$ & AF092138 \\
\hline & & $\begin{array}{l}\text { Homo sapiens } 12 \mathrm{kDa} \text { signal peptidase subunit, } \\
\text { mRNA }\end{array}$ & 450 & $e-124$ & HUMSP1S \\
\hline $34 a$ & Embryonic stem cells cDNA (AK010304) & no homology & & & \\
\hline $35 b$ & 18d embryo cDNA (AK003980) & no homology & & & \\
\hline $39 a$ & 11d embryo cDNA (AK019206) & WSB-1, mRNA & 2488 & 0.0 & NM019653 \\
\hline \multirow[t]{2}{*}{$40 \mathrm{a}$} & 18d embryo cDNA (AK003443) & $\begin{array}{l}\text { Bos taurus smallest subunit }(6.4 \mathrm{kDa}) \text { of ubiquinol } \\
\text { cytochrome } \mathrm{c} \text { reductase } \\
\text { Homo sapiens smallest subunit }(6.4 \mathrm{kDa}) \text { of ubiquinol } \\
\text { cytochrome c reductase }\end{array}$ & $\begin{array}{l}172 \\
133\end{array}$ & $\begin{array}{l}4 e-43 \\
3 e-31\end{array}$ & $\begin{array}{l}\text { D55637 } \\
\text { D55636 }\end{array}$ \\
\hline & Adult male hippocampus cDNA (AK013513) & same as $40 a$ & & & \\
\hline $40 c$ & same as $40 a$ & & & & \\
\hline
\end{tabular}

Table 2. Secondary Blast. Some of the sequences from Table 1 that had significant alignment with a cDNA sequence were submitted to GenBank for a search of sequence homology (Secondary Blast). The results are presented in this table as well as scores and e values. A score is obtained from a local alignment without gaps of a pair of equal length segments, one from each of the two sequences being compared. A modification of the Smith-Waterman or Sellers algorithms finds all segment pairs whose scores can not be improved by extension or trimming. These are called high-scoring segment pairs or HSP scores. Because HSP scores tend to be higher if the alignments are longer, the e-value becomes necessary for statistical significance. The e-value is the probability of finding another homologous sequence with a higher score. Therefore, the smaller the e-value the more significant the results become. The accession number for GenBank of the known genes and cDNA sequences found are also shown. It is important to point out that the two genes characterized for this study were obtained from this secondary blast: WSB1 and SPC12. 


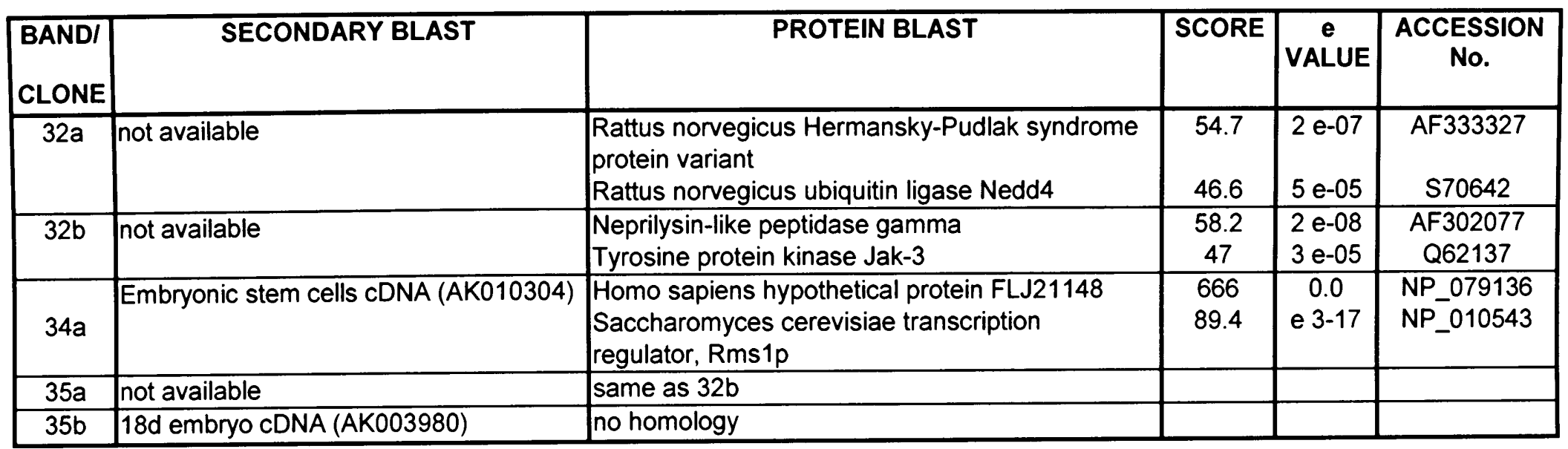

Table 3. Protein Blast. Some sequences were submitted to GenBank for a search of homology using a protein database. GenBank translates the submitted nucleotide sequence and searches for significant alignments with already existent translated sequences. Sequences from bands/clones $32 \mathrm{a}, 32 \mathrm{~b}$ and $35 \mathrm{a}$ were submitted for this search due to the arbitrary results obtained from the previous blasts. Sequences with no significant sequence homology after the secondary blast ( $34 \mathrm{a}$ and 35b) were also submitted to GenBank to search for homology with conserved protein domains. The results for this Blast are shown in this table as well as scores and e values. A score is obtained from a local alignment without gaps of a pair of equal length segments, one from each of the two sequences being compared. A modification of the Smith-Waterman or Sellers algorithms finds all segment pairs whose scores can not be improved by extension or trimming. These are called high-scoring segment pairs or HSP scores. Because HSP scores tend to be higher if the alignments are longer, the e-value becomes necessary for statistical significance. The e-value is the probability of finding another homologous sequence with a higher score. Therefore, the smaller the e-value the more significant the results become. The accession number for GenBank of the proteins and putative proteins obtained from this search is also shown. 


\section{Semiquantitative RT-PCR.}

Two bands were selected for characterization: 28 , corresponding to SPC12 the smallest subunit ( $12 \mathrm{kDa}$ ) of mammalian signal peptidase, and 39 , corresponding to WSB1 (a member of the SOCS family of negative regulators). For alignments refer to Appendix B and Appendix C.

In order to confirm the upregulation or downregulation of these two bands seen in the DD gel, semiquantitative RT-PCR was performed using the same cDNA obtained from the initial RT-PCR reaction. The results of semiquantitative PCR done on WSB1 and SPC12 are shown in Figure 4 and Figure 5, respectively. WSB1 was downregulated after induction with Edn3 which confirmed the results from the DD gel. However, after semiquantitative RT-PCR the opposite effect was seen for SPC12. In the DD gel, the band corresponding to SPC12 (28) is upregulated but appeared to be downregulated after subjected to semiquantitative RT-PCR.

\section{Characterization of $W S B 1$ and $S P C 12$ using whole-mount in-situ hybridization.}

Whole mount in-situ hybridization was the technique used to characterize the expression patterns of $W S B 1$ and SPC12. For comparison purposes, the expression pattern of WSB2 (another WD-40/SOCS protein) was also analyzed. In order to make the probes, ESTs containing a partial sequence of these genes were selected. All ESTs were obtained from mouse embryonic libraries and were cloned into vectors containing binding sites for the RNA polymerases adequate for riboprobe synthesis (T7, T3 and SP6). Expression analyses of $W S B 1, W S B 2$ and $S P C 12$ on whole-mount hybridized embryos at different stages of murine embryonic development are presented here. 


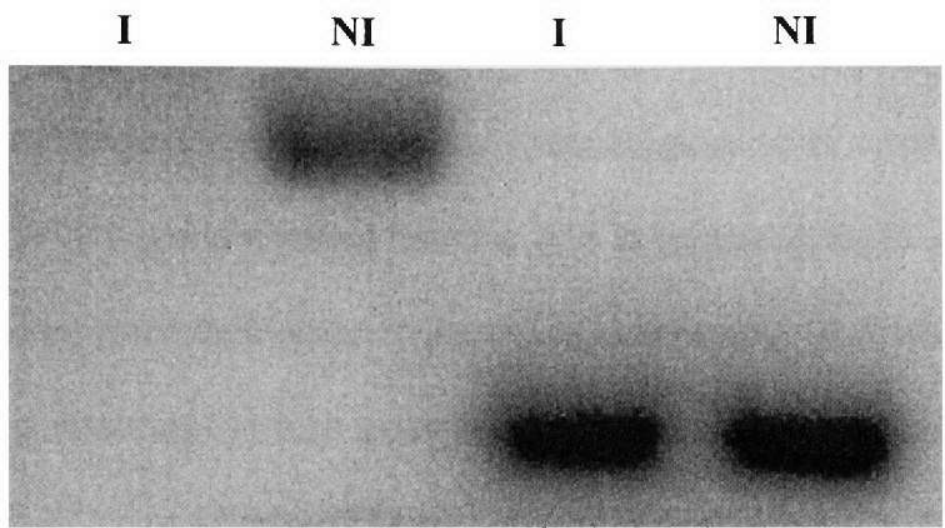

WSB-1
HPRTg
Figure 4. Semiquantitative PCR of WSB1. cDNA from induced (I) and non induced (NI) cultures were subjected to PCR using WSB-1 and HPRTg specific primers. HPRTg (a house keeping gene) was used as control comparison. The ratio of cDNA used was 8 (I) : 1 (NI).
I

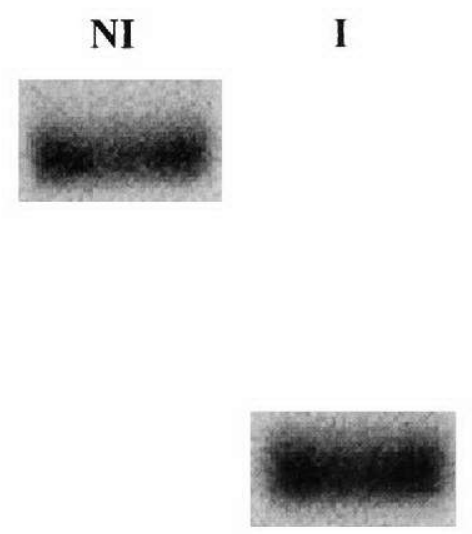

NI

Figure 5. Semi-quantitative PCR of SPC12 cDNA from induced (I) and non induced (NI) cultures were subjected to PCR using SPC12 and HPRTg specific primers. HPRTg (a house keeping gene) was used as control comparison. The ratio of cDNA used was $8(\mathrm{I}): 1(\mathrm{NI})$. 


\section{- WSB1 expression pattern.}

At 9.5dpc (Fig. 6A, B, C), WSB1 was highly expressed in the notochord as well as in the nephric duct. It was also expressed in the forebrain, hindbrain, migrating cranial neural crest cells and forming cranial ganglia. At $11.5 \mathrm{dpc}$ (Fig. 6D, E), it continued to be expressed in the hindbrain and also in the dorsal root ganglia and in the apical region of the developing limb buds. Cross-sections of $11.5 \mathrm{dpc}$ embryos hybridized with the WSB1 probe revealed that it is also expressed in the lateral aspect of the neural tube and confirmed expression in the dorsal root ganglia (Fig. 6G, H). It was also expressed in the genital ridge (which gives rise to the gonads), and in the limb buds (Fig. 6I).

At $12.5 \mathrm{dpc}$ (Fig. 6F), WSB1 appears to be downregulated since the hybridization signal was not as strong as in the previous stages. However, it still shows low levels of expression in the dorsal root ganglia as well as in the developing brain and limb buds.

WSB2 expression pattern was analyzed for comparison purposes. At 11.5dpc (Fig. 7A), it was highly expressed in the somites and the limb buds as well as in the brain. At $12.5 \mathrm{dpc}$ (Fig. 7B), WSB2 continued to be expressed in the same structures.

\section{- SPC12 expression pattern.}

At 11.5dpc (Fig. 8A), SPC12 was found to be expressed in the neural tube, in the dorsal root ganglia, in the forebrain and in the developing cartilage of the trunk. SPC12 was highly expressed in the limb buds as well as in the eye, and showed a peculiar pattern of expression in the liver. Cryosectioning allowed us to obtain cross sections of these whole-mount embryos. Sections of $11.5 \mathrm{dpc}$ (Fig. 8C, D) confirmed SPC12 expression in the eye, specifically in the lens, the iris and in the ciliary body. Sections through the 

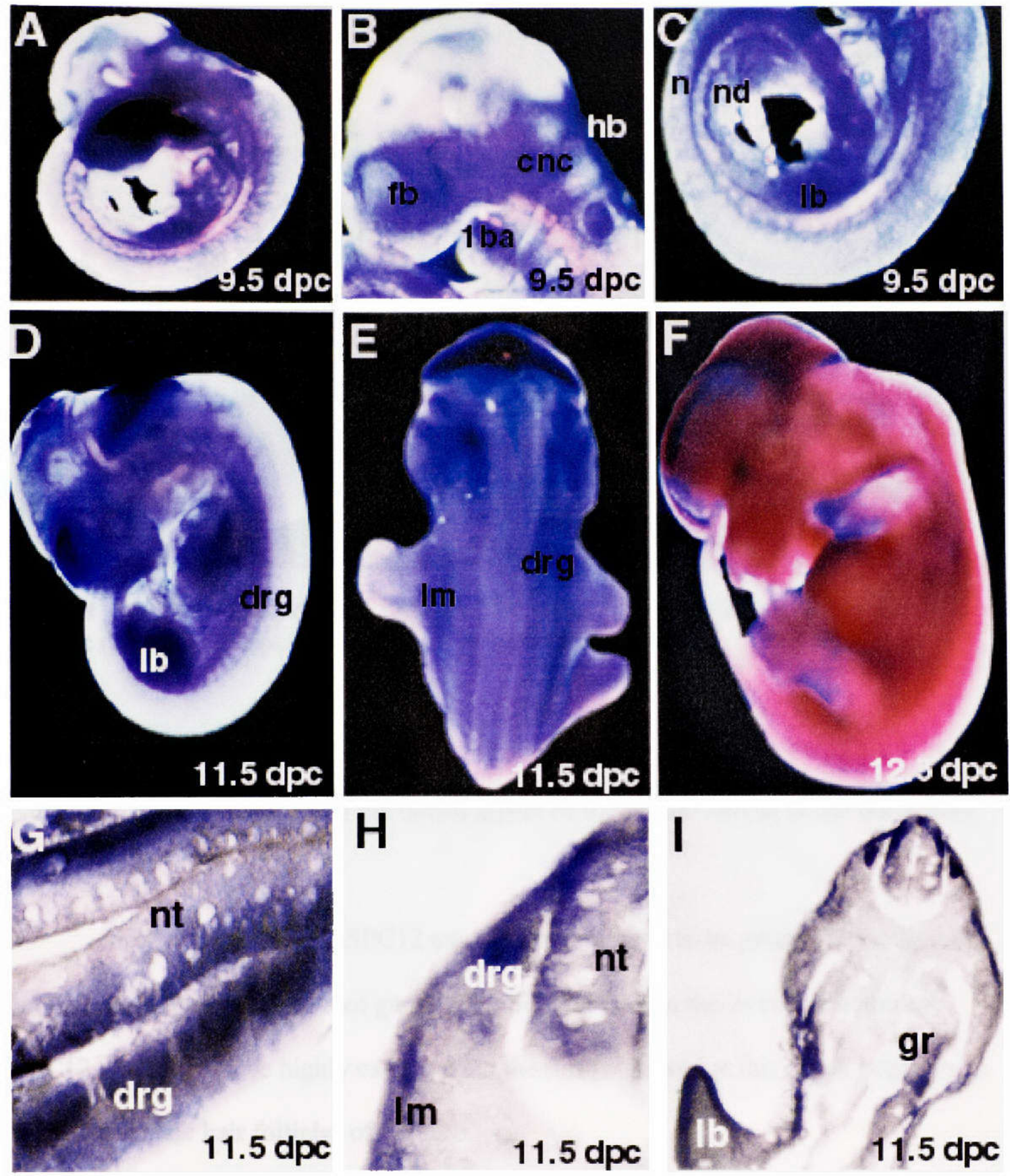

Figure 6. WSB1 expression pattern. Whole-mount in-situ hybridization of $9.5 \mathrm{dpc}$ (A, B, C), 11.5dpc (D, E) and 12.5dpc (F) embryos. Cross-sections (30um) of 11.5dpc whole-mount embryos (G, H, I). fb: forebrain, hb: hindbrain, cnc: cranial neural crest, 1ba: first branchial arch, n: notochord, nd: nephric duct, lb: limb bud, drg: dorsal root ganglia, lm: lateral mesenchyme, nt: neural tube, gr: genital ridge. 

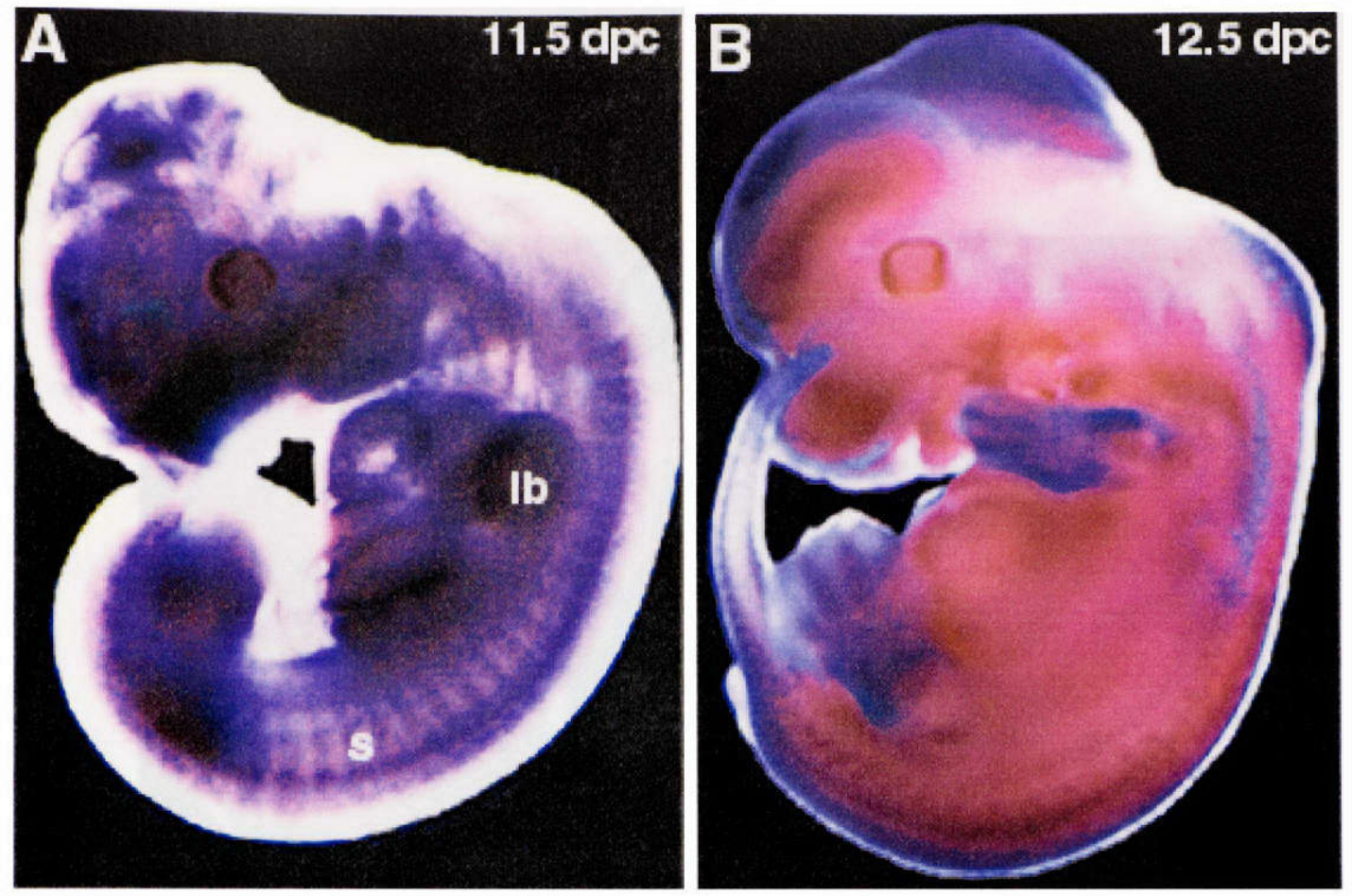

Figure 7. WSB2 expression pattern. Whole-mount in-situ hybridization of 11.dpc (A) and 12.5dpc (B) embryos. lb: limb buds, s: somites.

trunk confirmed expression in the dorsal aspect of the neural well as in the dorsal root ganglia.

At $12.5 \mathrm{dpc}$ (Fig. 8B), SPC12 expression continued to be present in the neural tube, in the adjacent dorsal root ganglia, in the forebrain, in the liver and in the eye. SPC12 continued to be highly expressed in the limb buds and at this stage, began to be expressed in the hair follicles of the face. 

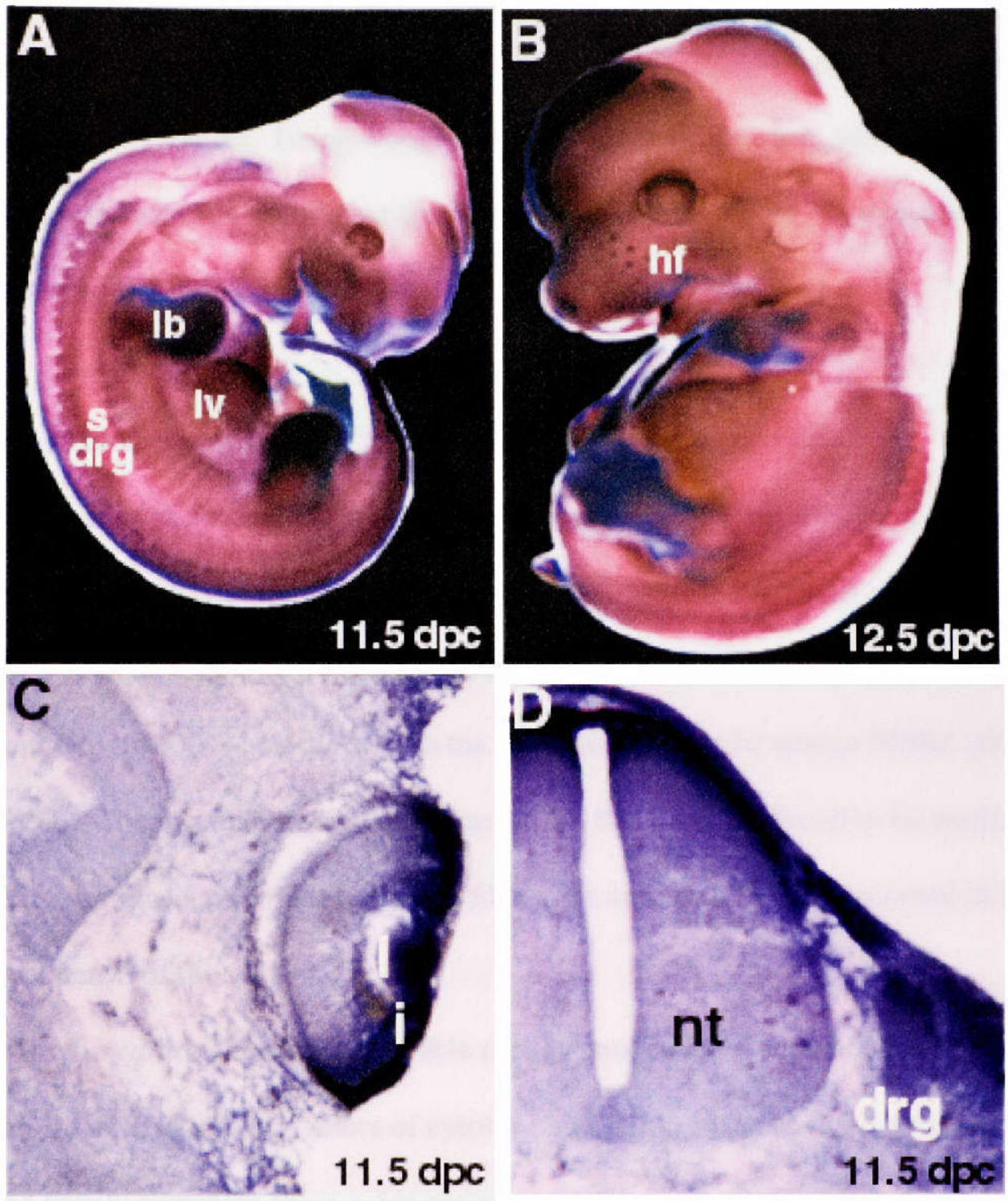

Figure 8. SPC12 expression pattern. Whole-mount in-situ hybridization of $11.5 \mathrm{dpc}(\mathrm{A})$ and $12.5 \mathrm{dpc}(\mathrm{B})$ embryos. lb: limb buds, lv: liver, s: somites, drg: dorsal root ganglia, hf: hair follicles, l: lens, i: iris, nt: neural tube. 


\section{DISCUSSION}

From the initial 30 bands selected for analysis, 11 showed significant sequence homology to previously identified gene sequences (Table 1). The first two genes identified in the course of this study were WSB1 and SPC12 and therefore, selected for expression pattern studies. Using whole-mount in-situ hybridization, the expression of both genes was analyzed at different stages of murine development. The results from this analysis can be found in the previous section (see Results).

\section{WSB1: A member of the SOCS family of negative regulators.}

Band 39 was among the first ones to be sequenced. When blasted, it showed $100 \%$ homology to a complete cDNA sequence obtained from an $11.5 \mathrm{~d}$ embryonic library (AN: AK019206). When this sequence was submitted again for a secondary blast, it was found to be $100 \%$ homologous to the sequence coding for mouse WSB1 (AN: NM019653). The original sequence obtained from band 39 was found to be homologous to the UTR (untranslated region) of the WSB1 gene and therefore not included in the mRNA sequence of the gene.

A review of the literature available on this gene revealed that WSB1 is a member of the family of SOCS (suppressors of cytokine signaling) proteins. The recently identified family members share a denominated SOCS box carboxy-terminal to distinct domains characteristic of each subfamily. While the original SOCS proteins contain SH2 domains, WSB1 and WSB2 contain WD-40 repeats amino-terminal to the SOCS box.

\section{- SOCS: Suppressors of cytokine signaling.}


Edn3 can also be classified as a cytokine because it is a protein that informs the cell about its surrounding environment. The kind of signal they convey and the specific cell response obtained depend on the type of cell targeted as well as the biological process in which they are involved (Nicola, 1994). Cytokines are known to control processes such as proliferation, growth, differentiation, immune and hematopoietic responses, as well as anti-apoptotic signals (Leonard, 1999). Extensive research on their mode of action led to the finding of a family of tyrosine kinases involved in many signaling pathways induced by cytokines. The Janus family of tyrosine kinases (Jak kinases) and signal transducers and activators of transcription (STATs) were among the first to be identified as active entities of a transducing pathway from the cell surface to the nucleus.

Jak kinases were physically associated to cytokine receptors when Withuhn et al. (1993) and Argetsinger et al. (1993) demonstrated there was an interaction between Jak2 ${ }^{7}$ and the erythropoietin and growth hormone receptors, respectively. The binding of their respective cytokine to these receptors induces receptor dimerization or oligomerization resulting in a juxtaposition of associated Jaks. These cross-phosphorylate causing enzymatic activation and in turn phosphorylate the receptor at multiple residues of its cytoplasmic domain (reviewed by Darnell, 1997). This creates docking sites for STATs (containing an SH2 binding domain) which are phosphorylated by active Jaks. STATs subsequently dimerize and are translocated to the nucleus where they activate the transcription of their target genes (reviewed by Imada, K. and Leonard, W.J., 2000).

\footnotetext{
${ }^{7}$ It is important to note that four mammalian Jak kinases have been identified: Jak1, Jak2, Jak3 and Tyk2 (Horvath and Darnell, 1997; Leonard and O'Shea, 1998). Interestingly, Jak3 and Tyk2 were identified during the course of this study (see BLAST results Table 1,2 and 3).
} 
Although it is broadly accepted that cytokine signaling involves associated kinases, it is also well known that the signal they convey needs to be regulated in magnitude and duration (Krebs and Hilton, 2000). This is when the need for negative regulators, such as SOCS proteins (suppressors of cytokine signaling), becomes critical. The first member of the SOCS family of negative regulators to be identified was CIS (now called CIS1), for cytokine-inducible SH2 containing protein (Yoshimura et al., 2000). It was found to be an early downstream gene of IL-2, IL-3, and EPO signaling (Yoshimura et al., 2000). The second family member, SOCS1, was identified by three groups. The first group cloned it as an inhibitor of IL-6 signaling in the myeloid leukemia cell line M1 and gave it the name of suppressor of cytokine signaling: SOCS (Starr et al., 1997). The second group identified it as an SH2 containing protein that binds Jak kinases and named it JAB for Jak-binding protein (Endo et al., 1997); and Naka et al., identified it using an antibody that recognized the $\mathrm{SH} 2$ binding domain of STAT3 to look for novel STAT familiy members. However, they found that the novel member was nothing else but, SOCS1. They called it SSI-1 for STAT-induced STAT-inhibitor.

CIS and SOCS1 transcription is rapidly induced after exposure to a range of cytokines and both of them can inhibit cytokine signaling capabilities but in different ways. CIS competes with STAT for docking sites in the receptor (Yoshimura et al., 1995) whereas SOCS1 binds to JAK kinases inhibiting their catalytic activity (Endo et al., 1997; Yasukawa et al., 1999).

A study conducted by Hilton et al. (1998) in which the predicted amino acid sequence of SOCS1 was submitted for homology to databases revealed that there were as many as six other proteins that contained and SH2 binding domain (SOCS2 to SOCS7) 
and as many as twenty that shared a conserved 40-amino-acid carboxyl-terminal denominated, the SOCS box. Despite their common denominator, these twenty novel proteins were divided into five structural classes according to the domains they exhibit upstream of the SOCS box. The SOCS family (SOCS1 to SOCS7; CIS) contains an SH2 binding domain; the other proteins contain instead ankyrin repeats (ASB1 to ASB4), SPRY domains (SSB1 to SSB3), GTPase-like domains, or WD-40 motifs. Two proteins containing WD-40 repeats have been identified: WSB1 and WSB2 (Hilton et al., 1998).

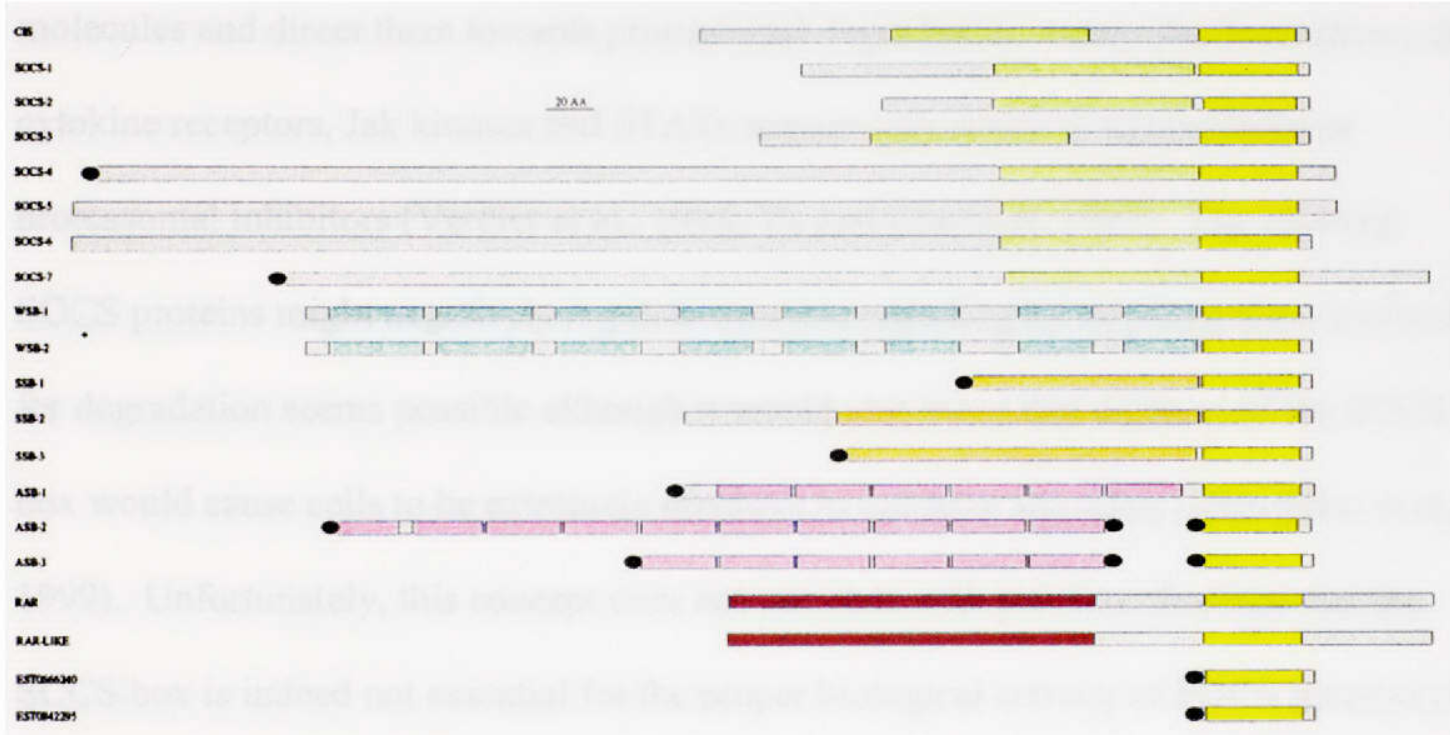

Figure 9. SOCS proteins. Diagram representing the twenty novel proteins identified which contain a common SOCS box (yellow). Green bars indicated $\mathrm{SH} 2$ domains, blue bars indicate WD-40 repeats, pink bars indicate ankyrin repeats, peach indicates SPRY domains and red indicates GTPase domains (from Hilton et al., 1998).

Although the SOCS box is conserved in all family members, research on its functionality is still underway. Early studies suggested that it is dispensable for the inhibitory activity of SOCS1 and SOCS3 (Nicholson et al., 1999; Narazaki et al., 1998). Other studies suggest that it is an active part in protein turnover in all family members 
(reviewed by Alexander et al., 1999). It has recently been suggested that the SOCS box interacts with elongins $\mathrm{B}$ and $\mathrm{C}$ because of their sequence similarity to regions of the von Hippel-Lindau tumor suppressor protein and elongin A, both of which bind to elongins $B$ and C (Kamura et al., 1998; Zhang et al., 1999). However, Kamura et al. propose that the interaction with elongins extends SOCS protein half-life. On the other hand, since elongin B has a ubiquitin-like sequence able to interact with proteasomal proteins and since CIS has been shown to be ubiquitinated and sensitive to proteasomal degradation (Verdier et al., 1998), Zhang et al. (1999) suggest that SOCS proteins interact with bound molecules and direct them towards proteasomal degradation. It has also been shown that cytokine receptors, Jak kinases and STATs remain very active in the presence of proteasomal inhibitors (Verdier et al., 1998; Yu and Burakoff, 1997). The idea that SOCS proteins might negatively regulate cytokine signaling by targeting these molecules for degradation seems possible although it would also mean that deletion of the SOCS box would cause cells to be extremely sensitive to cytokine signaling (Alexander et al., 1999). Unfortunately, this concept does not correlate with previous findings that the SOCS box is indeed not essential for the proper biological activity of SOCS proteins (see above).

\section{- WSB1 and WSB2}

WSB1 and WSB2 were identified as members of the SOCS family of proteins after a study revealed that they also contain (together with other 18 proteins) the conserved 40-amino-acid carboxyl-terminal sequence denominated, SOCS box (Hilton et al., 1998). WSB1 and WSB2 differ from the original SOCS proteins in the domain they 
exhibit amino-terminal to the SOCS box. WSB1 and WSB2 contain WD-40 repeats upstream of the SOCS box, whereas other SOCS proteins contain SH2 binding domains, ankyrin repeats, SPRY domains or GTPase-like domains.

WD-40 repeats are conserved core units that usually end with Trp-Asp (WD) and were first identified in $\beta$-subunits of heterotrimeric GTP-binding proteins. WD-40 domains contain a region of variable length followed by a residue core of somewhat constant length ( 40 amino acids) which is flanked by two characteristic pattern elements, GH (Gly-His) and WD (reviewed by Neer et al., 1994). Analysis of the structure of human WSB1 allowed the identification of eight WD-40 repeats (Kehrer-Sawatzki et al., 1999). However, WD-proteins do not have a common function. Some of the already identified proteins containing this motif have functions that range from playing a role in signal transduction to RNA splicing (Neer et al., 1999). Therefore, the function of WSB1 cannot be specified based on its WD structure.

Human WSBI has also been identified, mapped to chromosome 17 , and found to be close to the neurofibromatosis type 1 locus (Kehrer-Sawatzki et al., 1999). Additionally, an avian homolog of WSB1 has also been identified: Swip1. Studies of Swipl have revealed that its expression is regulated by Sonic Hedgehog (Shh) signaling in the developing somites and in the developing limb buds (Vasiliauskas et al., 1999). Swipl was also found to be expressed in the dorsal and ventral aspects of the neural tube, in the notochord, in the intermediate mesoderm (which gives rise to the urogenital system) at stage 10 (equivalent to the mouse $9.5 \mathrm{dpc}$ stage), and later on found to have strong expression in the branchial arches (stage 20). From stage 18 through stage 28 , 
Swipl showed expression in the limb buds; and, from stage 20 through 29 it was found to be expressed in the gut (Vasiliauskas et al., 1999).

Analysis of the expression pattern of WSB1 and WSB2 has revealed that they are expressed by certain neural crest derived cells as well as other non-neural crest derivatives. At $9.5 \mathrm{dpc}$, WSB1 was expressed in the migrating cranial neural crest but also, in the developing brain, the nephric duct, the developing limb buds (apical region) and in the notochord. At 11.5dpc, WSB1 continued to be expressed in these same structures (with the exception of the notochord and the nephric duct) as well as in the lateral aspect of the neural tube and the adjacent dorsal root ganglia. At $12.5 \mathrm{dpc}$, WSB1 appeared to be downregulated but was still expressed at low levels in the dorsal root ganglia and the developing brain. Analysis of the expression of WSB2 revealed that it is expressed in the somites, the developing limb buds, and the brain from 11.5dpc through $12.5 \mathrm{dpc}$.

Neither $W S B 1$ expression nor $W S B 2$ expression alone shows the same pattern as Swipl. However, if both patterns are combined, the resulting pattern is very similar to that of Swip1. This suggests that murine WSB1 and WSB2 might have diverged from the primitive avian Swipl during a duplication event.

\section{- WSB1 as a downstream target of Edn3 signaling.}

Comparison of the expression patterns of $W S B I$ and $E d n r B$ show partial overlap. $W S B 1$ and $E d n r B$ are both expressed in some neural crest derivatives such as the cranial crest $(9.5 \mathrm{dpc})$ and the dorsal root ganglia $(11.5-12.5 \mathrm{dpc})$. This overlap suggests that if 
$W S B 1$ expression is, indeed, downregulated by Edn3 signaling, this regulation might take place in the cells that form the structures in which WSBI and $E d n r B$ expression overlap. In addition, because WSB1 has been shown to bind Elongin BC (Kamura et al., 1998) and a module composed of a member of the cullin family (Cul5) and a RING-H2 finger protein $(\mathrm{Rbx} 1)$ to reconstitute potential ubiquitin ligases (Kamura et al., 2001), downregulation of $W S B 1$ following Edn3 signaling might prevent ubiquitination ${ }^{8}$ of key proteins, such as $\mathrm{pkC}$ and MAP kinase, that act downstream of the Edn3/EdnrB signaling pathway.

Certain cullin family members have been shown to associate with other proteins, such as Skp1, to also form ubiquitin ligase complexes. The complex formed by Skp1/Cul1/F-box (SCF-like ubiquitin ligase) has been found to continuously degrade $\beta$ catenin in the cytoplasm, which is found downstream of the Wnt/Frizzled signaling pathway (Latres et al., 1999). $\beta$-catenin has been identified as a transcription factor and also functions as a tumor suppressor. Mutations affecting members of the Wnt/Frizzled signaling pathway lead to an abnormal increase of $\beta$-catenin activity which, in turn, leads to the activation of genes involved in cell division (Gilbert, 2000). Because WSB1 binds a member of the cullin family and has ubiquitin ligase activity, it might be possible that its assembly with these proteins leads to the degradation of certain transcription factors that activate genes involved in cell proliferation, as in the case of SCF and $\beta$-catenin. Therefore, if Edn3 downregulates the expression of WSB1, the ubiquitin ligase activity of

\footnotetext{
${ }^{8}$ Ubiquitin ligases (E3) play a role in ubiquitination (targeting of proteins for degradation) by facilitating the formation of isopeptide bonds between the carboxyl-terminus of ubiquitin and lysine residues in the target protein or on the last ubiquitin of a protein-bound multiubiquitin chain. Proteins linked to multiubiquitin chains are potent signals for proteosomal degradation (reviewed by Ciechanover, 1998).
} 
the complex formed by WSB1/Cul5/ElonginBC can be potentially decreased, preventing the degradation of transcription factors that activate genes involved in cell proliferation.

\section{SPC12: The smallest subunit $(12 \mathrm{kD})$ of the signal peptidase complex.}

When the sequence of band 28 from the differential display was blasted, it was found to be highly homologous to a cDNA sequence obtained from the pancreas of a 10 day old male mouse (AN: AK0077336). A subsequent blast of this sequence gave us no significant homology to any other nucleotide sequences from GenBank. However, a translated blast against the protein database of GenBank gave high homology to the smallest subunit (12kDa) of the signal peptidase complex (see Table 1). Little information is available on signal peptidases and it was only recently that the $12-\mathrm{kDa}$ subunit of the mammalian signal peptidase complex was cloned (Kalies and Hartmann, 1996).

Signal peptidases generally cleave off signal sequences of secretory and membrane proteins in the lumen of the endoplasmic reticulum (ER), during protein translocation across the membrane of the ER (reviewed by von Heijne, 1994). However, the signal peptidase complex is possibly also involved in other proteolytic events in the ER membrane such as further digesting cleaved signal peptides (Lyko et al., 1995) or degrading membrane proteins in yeast (Mullins et al., 1995).

Mammalian signal peptidase was purified from canine pancreas microsomes as a complex of five polypeptide subunits: SPC25, SPC22/23, SPC21, SPC18 and SPC12 (Evans et al., 1986). SPC18, SPC21 and SPC 22/23 are single-spanning membrane proteins that have the majority of their domains in the lumen of the ER (Shelness et al., 
1993) and are similar in sequence to leader peptidase (van Dijl et al., 1992), the enzyme that cleaves signal sequences during translocation of proteins across the plasma membrane in bacteria (Zwizinski and Wickner, 1980). As a result, these polypeptides are thought to also play a catalytic role in cleavage of signal peptides in eukaryotes.

Conversely, SPC12 and SPC25 were found to span the membrane twice and to be largely exposed to the cytosolic compartment with very few amino acid residues in the lumen of the ER (Kalies and Hartmann, 1996). Since the active site of the signal peptidase complex is in the lumen, it is improbable that SPC12 and SPC25 take part in the catalytic activity of the enzyme. Furthermore, studies done on yeast have shown that Spclp (yeast homolog of SPC12) is non essential for proteolytic cleavage of certain precursor proteins or for the degradation of proteins (Fang et al., 1996). It has also been found that yeast mutants lacking Spc1p and Spc2p (homolog of SPC25) are able to grow relatively well when compared to wild type yeast, suggesting that the signal peptidase complex can still be active in the absence of two of its subunits (Mullins et al., 1996). However, Spclp does seem to be important for efficient signal peptidase activity (Fang et al., 1996).

It has also been shown that Sec11p (homologous to SPC18 and SPC21) is essential for cell viability (Bohni et al., 1988) and cleavage of tested precursor proteins (Mullins et al., 1995), suggesting that it contains the catalytic site. A study using Sec1lp mutants (sec11, temperature sensitive allele) revealed that when they are exposed to high temperatures, they rapidly accumulate precursors of secretory proteins and stop growing (Bohni et al., 1988). A more recent study showed that overexpression of Spclp suppressed the secll temperature-sensitive phenotype and increased the amount of precursor proteins cleavage found in the secll mutant, whereas depletion of Spclp 
exacerbated the sec11 defect (Fang et al., 1996), suggesting that it might play a role in the efficiency of the complex.

There is no more information about the function of yeast Spclp or mammalian SPC12. Being part of such a ubiquitous complex, it was surprising to find that SPC12 has a restricted expression pattern during development. Because it has been shown that SPC12 is not part of the active site of the signal peptidase, it might be possible that it has an alternative function during embryonic development. Due to the scarce information on this specific subunit, one can only speculate that if SPC12 is indeed involved in posttranslational modifications, it might play a role in the cleavage of precursor proteins whose transcription has been induced indirectly by the Edn3/EdnrB pathway.

\section{Concluding Remarks}

The role that the two genes characterized in this study play during development is yet to be established. Both of them were found to be expressed by neural crest derived cells which suggests that they might play a part in the development of these cells. However, subsequent functional studies, such as a knock-out, might help us identify those cell lineages whose proper differentiation depends upon the function of WSB1 or SPC12. In the case of WSB1, because of its ubiquitin ligase activity, enzymology assays would help identify the substrate targeted by the WSB1/Cul5/ElonginBC complex. In the case of SPC12 it would be interesting to analyze the expression patterns of the other subunits of the signal peptidase. If the other subunits share the same expression pattern, then SPC12 might be acting during development as part of the signal peptidase complex. If the 
expression patterns are not the same, then SPC12 could be playing an alternate role during the development of the cells expressing it.

It is important to note that the technique used in this study for identifying differentially expressed genes, DD RT-PCR, is not completely accurate. Although, DD RT-PCR is inexpensive, not difficult to carry out and yields plenty of information to be analyzed, it can convey misleading artifacts. For example, band 28 , which corresponded to SPC12, was shown to be upregulated after Edn3 induction in the DD gel. However, after repeated trials of semiquantitative PCR, SPC12 was shown to be downregulated after Edn3 induction. Such contradictions lead to lay emphasis on the drawbacks of selecting this technique for similar studies.

Although only two genes have been characterized for this study, the remaining genes identified and listed in Tables 1, 2 and 3 are yet to be characterized. Characterization of the latter is strongly suggested for ensuing projects as well as functional studies of WSB1 and SPC12. Characterizing the expression pattern and uncovering the function of more genes found downstream of Edn3 signaling could identify possible players in NCC development and eventually lead to the emergence of a novel regulatory pathway. 


\section{REFERENCES}

Alberts, B., Bray, D., Lewis, J., Raff, M., Roberts, K., Watson, J.D. (1994) Molecular Biology of The Cell. Third Edition. Garland Publishing Inc., New York, New York.

Alexander, W.S., Starr, R., Metcalf, D., Nicholson, S.E., Farley, A., Elefanty, A.G., Brysha, M., Kile, B.T., Richardson, R., Baca, M., Zhang, J., Willson, T.A., Viney, E.M., Sprigg, N.S., Rakar, S., Corbin, J., Mifsud, S., DiRago, L., Cary, D., Nicola, N.A., Hilton, D.J. (1999) Suppressors of cytokine signaling (SOCS): negative regulators of signal transduction. J. Leuk. Biol. 66:588-592

Anderson, D.J. (1997) Cellular and molecular biology of neural crest cell lineage determination. Trends Genet. 13:276-280

Aramori, I. and Nakanishi, S. (1992) Coupling of two endothelin receptor subtypes to differing signal transduction in transfected Chinese hamster ovary cells. J. Biol. Chem. 267:12468-12474

Argetsinger, L.S., Campbell, G.S., Yang, X., Witthuhn, B.A., Silvennoinen, O., Ihle, J.N., Carter-Su, C. (1993) Identification of JAK2 as a growth hormone receptorassociated tyrosine kinase. Cell 74:237-244

Barsh, G.S. (1996) The genetics of pigmentation: from fancy genes to complex traits. Trends Genet. 12:299-305

Baynash, A.G., Hosoda, K., Giaid, A., Richardson, J.A., Emoto, N., Hammer, R.E., Yanagisawa, M. (1994) Interaction of endothelin-3 with endothelin B receptor is essential for development of epidermal melanocytes and enteric neurons. Cell 79:1277-1285

Bloch, D., Eddy, R., Shows, T., Quertermous, T. (1989) cDNA cloning and chromosomal assignment of the gene encoding endothelin-3. J. Biol. Chem. 264:18156-18161

Bohni, P.C., Deshaies, R.J., Schekman, R.W. (1998) SEC11 is required for signal peptide processing and yeast cell growth. J. Biol. Chem. 106:1035-1042

Ceccherini, I., Zhang, A.L., Matera., I., Yang, G., Devoto, M., Romeo, G., and Cass, D.T. (1995) Interstidial deletion of the endothelin-B receptor gene in the spotting lethal (sl) rat. Hum. Mol. Genet. 4:2089-2096

Chakravarti, A. (1996) Endothelin receptor-mediated signaling in Hirschsprung disease. Hum. Mol. Genet. 5:303-307

Ciechanover, A. (1998) The ubiquitin-proteasome pathway: on protein death and cell life. EMBO J. 15:7151-7160 
Clouthier, D.E., Hosoda, K., Richardson, J.A., Williams, S.C., Yanagisawa, H., Kuwaki, T., Kumada, M., Hammer, R.E., Yanagisawa, M. (1998) Cranial and cardiac neural crest defects in endothelin-A receptor deficient mice. Development $125: 813-824$

Dupin, E., Glavieux, C., Vaigot, P., Le Douarin, N.M. (2000) Endothelin 3 induces the reversion of melanocytes to glia through a neural crest-derived glial-melanocytic progenitor. Proc. Natl. Acad. Sci. USA 97:7882-7887

Endo, T.A., Masuhara, M., Yokouchi, M., Suzuki, R., Sakamoto, H., Mitsui, K., Matsumoto, A., Tanimura, S., Ohtsubo, M., Misawa, H., Miyasaki, T., Leonor, N., Taniguchi, T., Fujita, T., Kanakura, Y., Komiya, S., Yoshimura, A. (1997) A new protein containing an SH2 domain that inhibits JAK kinases. Nature 387: 924-929

Evans, E.A., Gilmore, R., Blobel, G. (1986) Purification of microsomal signal peptidase as a complex. Proc. Natl. Acad. Sci. USA 83:581-585

Fang, H., Panzner, S., Mullins, C., Hartmann, E., Green, N. (1996) The homologue of mammalian SPC12 is important for efficient signal peptidase activity in Saccharomyces cerevisiae. J. Biol. Chem. 271:16460-16465

Gariepy, C.E., Williams, S.C., Richardson, J.A., Hammer, R.E., Yanagisawa, M. (1998) Transgenic expression of the endothelin-B receptor prevents congenital aganglionosis in a rat model of Hirschsprung disease. J. Clin. Invest. 102:10921101

Gilbert, S. (1997) Developmental Biology. Fifth Edition. Sinauer Associates Inc., Sunderland, Massachussets.

Groves, A.K. and Anderson, D.J. (1996) Role of the Environmental Signals and Transcriptional Regulators in Neural Crest Development. Dev. Genet. 18:64-72

Hilton, D.J., Richardson, R.T., Alexander, W.S., Viney, E.M., Willson, T.A., Sprigg, N.S., Starr, R., Nicholson, S.E., Metcalf, D., Nicola, N.A. (1998) Twenty proteins containing a C-terminal SOCS box form five structural classes. Proc. Natl. Acad. Sci. USA 95:114-119

Hofstra, R.M., Osinga, J., Tan-Sindhunata, G., Wu, Y., Kamsteeg, E.J., Stulp, R.P., van Ravenswaaij-Arts, C., Majoor-Krakauer, D., Angrist, M., Chakravarti, A., Meijers, C., Buys, C.H. (1996) A homozygous mutation in the endothelin-3 gene associated with a combined Waardenburg type 2 and Hirschsprung phenotype (Shah-Waardenburg syndrome). Nat. Genet. 12:445-447

Horvath, C.M., Darnell, J.E. (1997) The state of the STATs: recent developments in the study of signal transduction to the nucleus. Curr. Opin. Cell Biol. 9:233-239 
Hosoda, K., Hammer, R.E., Richardson, J.A., Baynash, A.G., Cheung, J.C., Giaid, A., Yanagisawa, M. (1994) Targeted and natural (piebald-lethal) mutations of endothelinB receptor gene produce megacolon associated with spotted coat color in mice. Cell 79:1267-1276

Imada, K. and Leonard, W.J. (2000) The Jak-STAT pathway. Molecular Immunology $37: 1-11$

Imamura, F., Arimoto, I., Fujiyoshi, Y., Doi, T. (2000) W276 mutation in the endothelin receptor subtype B impairs $\mathrm{Gq}$ coupling but not $\mathrm{Gi}$ or Go coupling. Biochemistry 39:686-692

Inoue, A., Yanagisawa, M., Kimura, S., Kasuya, Y., Miyauchi, T., Goto, K., Masaki, T. (1989) The human endothelin family: three structurally and pharmacologically distinct isopeptides predicted by three separate genes. Proc. Natl. Acad. Sci. USA 86:2863-2867

Itoh, Y., Yanagisawa, M., Ohkubo, S., Kimura, C., Kosaka, T., Inoue, A., Ishida, N., Mitsui, Y., Onda, H., Fujino, M., Masaki, T. (1989) Cloning and sequence analysis of cDNA encoding the precursor of a human endothelium-derived vasoconstrictor peptide, endothelin: identity of human and porcine endothelin. FEBS Lett. 231:440-444

Jackson, I.J. (1991) Muse coat colour mutations: a molecular genetic resource which spans the centuries. Bioassays 13:439-446

Jackson, I. (1997) Homologous pigmentation mutations in human, mouse and other model organisms. Hum. Mol. Genet. 6:1613-162

Jan, Y.N. and Jan, L.Y. (1995) Genetic control of cell fate specification in Drosophila peripheral nervous system. Annu. Rev. Genet. 28:373-393

Kalies, K.U and Hartmann, E. (1996) Membrane topology of the 12- and the 25-kDa subunits of the mammalian signal peptidase complex. J. Biol. Chem. 271:39253929

Kamura, T., Sato, S., Haque, D., Liu, L., Kaelin, W.G., Jr., Conaway, R.C., Conaway, J.W. (1998) The elongin BC complex interactswith the conserved SOCS-box motif present in members of the SOCS, ras, WD-40 repeat, and ankyrin repeat families. Genes Dev. 12:3872-3881

Kamura, T., Burian, D., Yan, Q., Schmidt, S.L., Lane, W., Querido, E., Branton, P.E., Shilatifard, A., Conaway, R.C., Conaway, J.W. (2001) MUF1, a novel Elongin $\mathrm{BC}$-interacting leucine-rich repeat protein that can assemble with $\mathrm{Cul} 5$ and $\mathrm{Rbx} 1$ to reconstitute a ubiquitin ligase. J. Biol. Chem. 276:29748-29753 
Kehrer-Sawatzki, H., Maier, C., Moschgath, E., Elgar, G., Krone, W. (1999)

Characterization of three genes, AKAP84, BAW and WSB1, located 3 ' to the Neurofibromatosis type 1 locus in Fugu rubripes. Genes 235:1-11

Krebs, D.L. and Hilton, D.J. (2000) SOCS: physiological suppressors of cytokine signaling. J. Cell Sci. 113:2813-2819

Kurihara, Y., Kurihara, H., Suzuki, H., Kodma, T., Maemura, K., Nagai, R., Oda, H., Kuwaki, T., Cao, W.-H., Kamada, N. (1994) Elevated blood pressure and craniofacial abnormalities in mice deficient in endothelin-1. Nature 368:703-710

Kusuhara, M. Yamaguchi, D., Ohnishi, A., Abe, K., Kimura, S., Oono, H., Hori, S. and Nakamura, Y. (1989) Endothelin potentiates growth factor-stimulated DNA synthesis in Swiss 3T3 cells. Jpn. J. Cancer Res. 80:302-305

Lahav, R., Ziller, C., Dupin, E., Le Douarin, N.M. (1996) Endothelin 3 promotes neural crest cell proliferation and mediates a vast increase in melanocyte number in culture. Proc. Natl. Acad. Sci. USA 93:3892-3897

Latres, E., Chiaur, D.S., Pagano, M. (1999) The human F box protein beta-Trcp associates with the Cul1/Skp1 complex and regulates the stability of beta-catenin. Oncogene 18:849-854

Le Douarin, N.M. and Teillet, M.A. (1973) The migration of neural crest cells to the wall of the digestive tract in the avian embryo. J. Embryol. Exp. Morphol. 30:31-48

Le Douarin, N.M. (1982) The Neural Crest. Cambridge University Press, Cambridge, England.

Le Douarin, N.M. (1986) Cell Line Segregation during Peripheral Nervous System Ontogeny. Science 231:1515-1522

Le Douarin, N.M., Ziller, C, and Couly, G.F. (1993) Patterning of Neural Crest Derivatives in the Avian Embryo: In Vivo and in Vitro Studies. Dev.Biol. 159:2449

Le Douarin, N.M, Dupin, E. and Ziller, C. (1994) Genetic and epigenetic control in neural crest development. Curr. Biol. 4:685-695

Leibl, M.A., Ota, T., Woodward, M.N., Kenny, S.E., Lloyd, D.A., Vaillant, C.R., Edgar, D.H. (1999) Expression of endothelin 3 by mesenchymal cells of embryonic mouse caecum. Gut 44:246-252

Leonard, W.J., O'Shea, J.J. (1998) Jaks and STATs: Biological implications. Annu. Rev. Immunol. 16:293-322 
Leonard, W.J. (1999) Type I cytokines and interferons and their receptors. In Fundamental Immunology, $4^{\text {th }}$ ed. Edited by W.E. Paul. Lippincott Raven Publishers, Philadelphia.

Lyko, F., Martoglio, B., Jungnickel, B., Rapoport, T.A., Dobberstein, B. (1995) Signal sequence processing in rough microsomes. J. Biol. Chem. 270:19873-19878

Mayer, Thomas (1965) The development of piebald spotting in mice. Dev. Biol. 11:319334

Mayer, Thomas (1967) Pigment cell migration in piebald mice. Dev. Biol. 15:521-535

Mullins, C., Lu, Y., Campbell, A., Fang, H., Green, N. (1995) A mutation affecting signal peptidase inhibits degradation of an abnormal membrane protein in Saccharomyces cerevisiae. J. Biol. Chem. 270:17139-17147

Mullins, C., Meyer, H.A., Hartmann, E., Green, N., Fang, H. (1996) Structurally related Spc1p and Spc2p of yeast signal peptidase complex are functionally distinct. $J$. Biol. Chem. 271:29094-29099

Naka, T., Narazaki, M., Hirata, M., Matsumoto, T., Minamoto, S., Aono, A., Nishimoto, N., Kajita, T., Taga, T., Yoshizaki, K., Akira, S., Kishimoto, T. (1997) Structure and function of a new STAT-induced STAT inhibitor. Nature 387: 924-929

Narazaki, M., Fujimoto, M., Matsumoto, M., Morita, Y., Saito, H., Kajita, T., Yoshizaki, K., Naka, T., Kishimoto, T. (1998) Three distinct domains of SSI-1/SOCS-1/JAB protein are required for its suppression of interleukin 6 signaling. Proc. Natl. Acad. Sci. USA 95:13130-13134

Nataf, N., Lecoin, L., Eichmann, A., Le Douarin, N.M. (1996) Endothelin-B receptor is expressed by neural crest cells in the avian embryo. Proc. Natl. Acad. Sci. USA 93:9645-9650

Nataf, N., Amemiya, A., Yanagisawa, M., Le Douarin, N.M. (1998) The expression pattern of endothelin 3 in the avian embryo. Mech. Dev. 73:217-220

Neer, E.J., Schmidt, C.J., Nambudripad, R., Smith, T.F. (1994) The ancient regulatoryprotein family of WD-repeat proteins. Nature 371:297-300

Nicholson, S.E., Willson, T.A., Farley, A., Starr, R., Zhang, J.G., Baca, M., Alexander, W.S., Metcalf, D., Hilton, D.J., Nicola, N.A. (1999) Mutational analysis of the SOCS proteins suggest a dual domain requirement but distinct mechanisms for inhibition of LIF and IL-6 signal transduction. EMBO J. 18:375-385

Nicola, N.A. (1994) An introduction to the cytokines. In Guidebook to Cytokines and Their Receptors. Edited by N.A. Nicola. Oxford University Press, Oxford. 
Opdecamp, K., Kos, L., Arnheiter, H., Pavan, W.J. (1998) Endothelin signaling in the development of neural crest-derived melanocytes. Biochem. Cell. Biol. 76:10931099

Pavan, W.J. and Tilghman, S. (1994) Piebald lethal (sl) acts early to disrupt the development of neural crest-derived melanocytes. Proc. Natl. Acad. Sci. USA 91:7159-7163

Phillips, P.E., Cade, C., Parker Botelho, L.H., Rubanyi, G. (1992) Molecular Biology of Endothelins in Endothelin. Edited by G. Rubanyi. Oxford University Press, Oxford.

Puffenberger, E.G., Hosoda, K., Washington, S.S., Nakao, K., deWit, D., Yanagisawa, M., Chakravarti, A. (1994) A missense mutation of the endothelin-B receptor gene in multigenic Hirschsprung's disease. Cell 79:1257-1266

Reid, K., Turnley, A.M., Maxwell, G.D., Kurihara, Y., Kurihara, H., Bartlett, P.F., Murphy, M. (1996) Multiples roles for endothelin in melanocyte development: regulation of progenitor number and stimulation of differentiation. Development $122: 3911-3919$

Rice, J., Doggett, B., Sweetser, D.A., Yanagisawa, H., Yanagisawa, M., Kapur, R.P. (2000) Transgenic rescue of aganglionosis and piebaldism in lethal spotted mice. Dev. Dynamics 217:120-132

Riethmacher, D., Sonnenberg-Riethmacher, E., Brinkmann, V., Yamaai, T., Lewin, G.R. and Birchmeier, C. (1997) Severe neuropathies in mice with targeted mutations in the ErbB receptor. Nature 389:725-737

Santschi, E.M., Purdi, A.K., Valberg, S.J., Vrotsos, P.D., Kaese, H., and Mickelson, J.R. (1998) Endothelin receptor B polymorphism associated with lethal white foal syndrome in horses. Mamm. Genome 9:306-309

Sha, N.M., Groves, A.K. and Anderson, D.J. (1996) Alternative neural crest cell fates are instructively promoted by TGF $\beta$ superfamily members. Cell 85:331-343

Shin, M.K., Russell, L.B., and Tilghman, S.M. (1999) The temporal requirement for endothelin receptor-B signalling during neural crest development. Nature 402:496-501

Schuchardt, A., D’Agati, V., Larsson-Bloomberg, L., Constantini, F., Pachnis, V. (1994) Defect in the kidney and enteric nervous system of mice lacking the tyrosine kinase receptor Ret. Nature 367:380-383

Shelness, G.S., Lin, L., Nicchitta, C.V. (1993) Membrane topology and biogenesis of eukaryotic signal peptidase. J. Biol. Chem. 268:5201-5208 
Southard-Smith, E.M., Kos, L., Pavan, W.J. (1998) Sox 10 mutation disrupts neural crest development in Dom Hirschsprung mouse model. Nat. Genet. 18:60-64

Starr, R., Willson, T.A., Viney, E.M., Murray, L.J., Rayner, J.R., Jenkins, B.J., Gonda, T.J., Alexander, W.S., Metcalf, D., Nicola, N.A. (1997) A family of cytokineinducible inhibitos of signaling. Nature 387:917-21

Stone, J.G., Spirling, L.I., Richardson, M.K. (1997) The neural crest population responding to endothelin-3 in vitro includes multipotent cells. J. Cell Sci. 110:1673-1682

Takagi, Y., Ninomiya, H., Sakamoto, A., Miwa, S., Masaki, T. (1995) Structural basis of $\mathrm{G}$ protein specificity of human endothelin receptors. A study with endothelin $\mathrm{A} / \mathrm{B}$ chimeras. J. Biol. Chem. 270:10072-10078

Takayanagi, R., Ohnaka, K., Takasaki, C., Ohashi, M., Nawata, H. (1991) Multiple subtypes of endothelin receptors in porcine tissues: characterization by ligand binding, affinity labeling and regional distribution. Regul. Pept. 32:23-37.

van Dijl, J.M., de Jong, A., Vehmaanpera, J., Venema, G., Bron, S. (1992) Signal peptidase I of Bacillus subtilis: patterns of conserved amino acids in prokaryotic and eukaryotic type I signal peptidases. EMBO J. 11:2819-2828

Vasiliauskas, D., Hancock, S., Stern, C.D. (1999) Swip-1: novel SOCS box containing WD-protein regulated by signalling centres and by Shh during development. Mech. Dev. 82:79-94

Verdier, F., Chretien, S., Muller, O., Varlet, P., Yoshimura, A., Gisselbrecht, S., Lacombe, C., Mayeux, P. (1998) Proteasomes regulate erythropoietin receptor and signal transducer and activator of transcription 5 (STAT5) activation. J. Biol. Chem. 273:28185-28190

Vichi, P., Whelchel, A., Posada, J. (1999) Transmembrane helix 7 of the endothelin B receptor regulates downstream signaling. J. Biol. Chem. 274:10331-10338

von Heijne, G. (1994) Signal Peptidases . Edited by von Heijne. Landes Company, Austin, Texas.

Weston, J.A. (1963) A radioautographic analysis of the migration and localization of trunk neural crest cells in the chick. Dev. Biol. 6:279-310

Witthuhn, B.A., Quellee, F.W., Silvennoinen, O., Yi, T., Tang, B., Miura, O., Ihle, J.N. (1993) JAK2 associates with the erythropoietin receptor and is tyrosine phosphorylated and activated following stimulation with erythropoietin. Cell $74: 227-236$ 
Wu, J.J., Chen, J.X., Rothman, T.P., Gershon, M.D. (1999) Inhibition of in vitro enteric neuronal development by endothelin-3: Mediation by endothelin B receptors. Development 126:1161-1173

Yada, Y., Higuchi, K., Imokawa, G. (1991) Effects of endothelins on signal transduction and proliferation in human melanocytes. J. Biol. Chem. 266:18352-18357

Yanagisawa 1 , M., Kurihara, H., Kimura, S., Tomobe, Y., Kobayashi, M., Mitsui, Y., Yazaki, Y., Goto, K., Masaki, T. (1988) A novel potent vasoconstrictor peptide produced by vascular endothelial cells. Nature 332:411-415

Yanagisawa, M., Inhoue, A., Ishikawa, T., Kasuya, Y., Kimura, S., Nakajima, K., Watanabe, T.X.., Sakakibara, S., Goto, K., Masaki, T. (1988) Primary structure, synthesis and biological activity of rat endothelin, an endothelium-derived vasoconstrictor peptide. Proc. Natl. Acad. Sci. USA 85:6964-6968

Yanagisawa, H., Hammer, R.E., Richardson, J.A., Williams, S.C., Clouthier, D.E. (1998) Role of endothelin-1/endothelin-A receptor-mediated signaling pathway in the aortic arch patterning in mice. J. Clin. Invest. 102:22-33

Yasukawa, H., Misawa, H., Sakamoto, H., Masuhara, M., Sasaki, A., Wakioka, T., Ohtsuka, S., Imaizumi, T., Matsuda, T., Ihle, J.N., Yoshimura, A. (1999) The jakbinding protein $\mathrm{JAB}$ inhibits Janus tyrosine kinase activity through binding in the activation loop. EMBO J. 18:1309-1320

Yoshimura, A., Ohkubo, T., Kiguchi, T., Jenkins, N.A., Gilbert, D.J., Copeland, N.G., Hara, T., Miyajima, A. (1995) A novel cytokine-inducible gene encodes an SH2 containing protein that binds to tyrosine-phosphorylated interleukin 3 and erythropoietin receptors. EMBOJ. 14:2816-2826

Yu, C.-L., Burakoff, S.J. (1997) Involvement of proteasomes in regulating Jak-STAT pathways upon interleukin-2 stimulation. J. Biol. Chem. 272:14017-14020

Zhang, J.G., Farley, A., Nicholson, S.E., Willson, T.A., Zugaro, L.M., Simpson, R.J., Moritz, R.L., Cary, D., Richardson, R., Hausman, G., Kile, B.T., Kent, S.B.H., Alexander, W.S., Metcalf, D., Hilton, D.J., Nicola, N.A., Baca,M. (1999) The conserved SOCS box motif in suppressors of cytokine signaling binds to elongins $\mathrm{B}$ and $\mathrm{C}$ and may couple bound proteins to proteosomal degradation. Proc. Natl. Acad. Sci. USA 96:2071-2076

Zwizinski, C. and Wickner, W. (1980) Purification and characterization of leader (signal) peptidase from Escherichia coli. J. Biol. Chem. 255:7973-7977 


\section{APPENDICES}

\section{APPENDIX A}

Sequences from selected bands from the Differential Display gel.

4 clone a:

AAGCTTTTTTTTTTTCAAGGTCATTATTTATTTGTTGCTCTTAAAGACTCAT TTTTGACTGGACTCAGACTTAGAAGTAGAAGCTCTCAGTGAGGACAGCCT ACGTCTCTTGGCAATCAAGCTTA

clone b:

AAGCTTTTTTTTTTTCAAGGTCATTATTTATTTGTTGCTCTTAAAGACTCAT TTTTGACTGGACTCAGACTTAGAAGTAGAAGCTCTCAGTGAGGACAGCCT ACGTCTCTTGGCAATCAAGCTTA

clone c:

AAGCTTTTTTTTTTTCAAGGTCATTATTTATTTGTTGCTCTTAAAGACTCAT TTTTGACTGGACTCAGACTTAGAAGTAGAAGCTCTCAGTGAGGACAGCCT ACGTCTCTTGGCAATCAAGCTTA

9 clone a:

AAGCTTTTTTTTTTTCAAGGTCATTATTTATTTGTTGCTCTTAAAGACTCAT TTTTGACTGGACTCAGACTTAGAAGTAGAAGCTCTCAGTGAGGACAGCCT ACGTCTCTTGGCAATCAAGCTTATAACGCAGGAAAGAACATGNGAGCNA

clone b:

AAGCTTGATTGCCAAGAGACGTAGGCTGTCCTCACTGAGAGCTTCTACTT CTAAGTCTGAGTCCAGTCAAAAATGAGTCTTTAAGAGCAACAAATAAATA ATGACCTTGAAAAAAAAAAAGCTA

clone c:

AAGCTTTTTTTTTTTCATAAATCTCATCACTTTATTCGNTGGTGGGCAATCA AGCTTANGCCG

27 clone a:

AAGCTTGCACCATCAACAGTTCAGAATGTTCTTATTAATCCATCGGTAATT GGGTCCAAAAACATTCTTATTACTACTAATATGGTATCACAGAATACAGC CGAGTCAGCAAATGCACTGAAACGGAAACGTGAAGACGATGATGATGAC GATGATGACGATGATGATGATGACTATGATAATATGTAGTCTAGCCACGA TGCATGTAACCTGTGTTCTTGGACTTGGATCCATTGTACTACAAGTTAAAA 
AGCATGTTAGATGTTTTAAAGCTGTACTTTAGAAAGTGGTGTTTCATACGT ATGCTTTGCTTTTTGATTAAAATGTTCAGTTTTACTAGAACTAGTGATGGT TTTTCATCAACCTTTATGCACAAAAAATAAAATTGTCATTTATCAGTTTGA AAAAAAAAAAGCTTA

clone b: not available

clone c: not available

25 clone a:

AAGCTTTTACCGCCTAAATATCGTTTTGGTCAGTGAACTGCATATTACCAT AAGATGGTAATGGAGCTGAAAAATTCCTGGGACCTAGCGAGGTCACAGCT GTGATGATGTGTTTTACTCAGGTCTTGGTGCAAACAAGCCAGTGCATTGCC AGTCTTGTAAAAATGTAGCACAATTGTGTACAGTACATACTTGATAGTGC TAATAAATGGCTTACTGATCTATGTAAAAAAAAAAAGCTTA

clone b: not available

clone c: not available

27 clone a:

NTTTTNGAGCCCGAGTTNCTCNAGNCNCNACGTGTGCNATCTACATGCNT GCTCGAGCGGCCGCCACTTGACTATAGANNCNATATNGAACCCTCTNTAN GCNTGCTTACNGCNGCNNACACATTNNAAGNTANGGGGANNCATAGTAC NNNGGGNTGTACCNANCATGCTCAATNNCAANANTTTNTNNNANACTCTG NCCTAAGCCTGGCCCTTCTTNATCTGAAAGCACTACTACNAGCACTCCAT NAACNANNGNATACTGTTANTANNTAGATGNTGACACTATTAAACCTCCT CTGNTGTGTGGGTANNNAAAAAAAGCTTA

clone b:

CGCCCGANTNACTCCAGGCNCNACGTTGCNNTCTACATGCCTGCTCGAGG CGGNCCCCACTNNCTATAGATANTATATAGAACCCTCTNTTAANCTTCTAC CGCCNCTCANNCATTCCAAGTTANGGGGAANCATAGTACCANGGGCTGTA CCNANCATGCTCANNCCAANATTTTGTNNNANACTCTGCCCTANGCCTGC CCTTCTTCATCTGAAAGCACTACTACNNGCACTCCAGTGACNAAGGGATN CTNGTAATAATNNAGNNGCTGCCACTTATAAANCCTCCTTTGCTGGGGGG GTAAAAAAAAAANGNTNAGGGGGAAATTCNAAANCCTTGNCGGCNGTTN NTATNGAANCCAANCTCGNANCCANNNTTGNNGCNNACTTGGGGANTTT NNTANGGGANCCNAANTANNTNGCCAAATTNANGGCNNNANTNGNTTCN TNNGTNAAATGGCTNTCCGTTCCNATTCNACAAAGATNACAACCGGANCC 
ATAAAAAATAAANCCTGGGNCCCTATTGANNGAGCTAACTCNCNTTAATT GCGTNGNGCTCACTGCCCGGTNTCCAATGGGGGAANCCTGNCGCCCAANT TGGATTAANGAACCGNCNCCNTCCGGGGAGAGGNAATTTGCNTTTNGNGC NCTTTNACGATTCTCCCACACTGACTNGATNGGCCTNGGNCNTTNNNGTG NNTTATCCGTNTTNTCTCTCTNNAAAGNGGNNANNCGGTNTCCCNAAANC GGGGGANNCCCNGAAAANANATGGGGGCT

28 clone a:

AAGCTTTTACCGCCTATGTTCTTATAGCACAGCTGTGTCGAGATCTAATTG TCATGGCTTCATTTCTAATCCAAATGTATTTTAAGTTATGACTATTTTATAC CATCTCTTCATAAGCTTGTTATGGAGAACAGGAGATACAAGTATGCAATG CTTCTTTCCCGTGTGTATAATGAATAAACACTTCATAACTTGTAAAAAAAA AAAGCTTACAGAATCAGGGGATAACGCNG

clone b: not available

clone c: not available

30 clone a: not able to edit

clone b:

AAGCTTTTTTTTTTTCAATGTGTTATAACAAATGGATGTTNGGCTCANGAG CCCAGAACAGCCTCTCTATCAATCACAGCAGGCAGTTATCACATGGTAGG CTCCAAGGAGGAACTGTGTGCGCCCCAAGTGTCTGATGGCTGGCTGTACT TCTCTTCCAC

clone c:

AAGCTTTTTTTTTTTCAATGTGTTATAACAAATGGATGTTAGGCTCAGGAG CCCAGAACAGCCTCTCTATCAATCACAGCAGGCAGTTATCACATGGTAGG CTCCAAGGAGGAACTGTGTGCGCCCCAAGTGTCTGATGGCTGGCTGTACT TCTCTTCCAC

32 clone a:

AAGCTTTGGTCAGGCAAGGGGGAAGTACTAGGAGCAGCCATTATACACTG AGGTCAGAGGAGGGTGGCATAGCTGGTTGAGGTTGTGTTTGGAAAGGGCT TAAGAAAGACTCTGAGGGGCTCAGGAGTTAAGAGCACTGACCGCTCTTCC AGGGGTCCTGAGTTCAATTCCCAGTAACTACATGGTGGCTCACAGCCATC TGTAATGGGATCTGATGCCCTCTTCTGGTGTGTCTGAAGACAGAGACAGT GTATTCACGTACATGAAAAAAAAAAAGCTTA 
clone b:

AAGCTTTTTTTTTTTCGAGACAGGGTTTCTCTGTGTAGCCCTGGCTGTCCA GGAACTCACTTTGTAGACCAGGCTGTCCTCGAACTCANAAATCTGCCTGC CTCTGTCTCCCAAGTGCTGGGATTAAAGGGNGGNGGGGGACACCTTTACT AGACTTNCTTCTTATATATTTCATATCACAAATACNCCAGCTCCTTTATGG NTTTATTCTATTTGGGAATTATAGAAGGGATTCTAGGNTTNAAAAACATA ACAATGNGNATTGNAAAGCATAAAAAATGNTTAGACTCCTTAAACAGNC NAAGCTTAANGGGGAAATTCANCACACTGGGGGGCGGTCTAANGGA

clone c: not able to edit

34 clone a:

GCCCGGTNCTCCAGNCNCNACGNTGCNNTCTANTGCCTGCTCGAGCGGCC CGCCTNACTATAGANNNNAANNGACCCTCNCTATNCCTTCTCTCACGNAN GGCNATTCCACCAAAGGTNGNNGNATCCTTGNNAAGAGTTTNNGCTATCC TCGGGNTTTCGCCATNCCANATNAANTNNTTNGTACCACTTTTGGGATTA NNTCTGGTTTGAGAGGANAGAAAANCTATTNCATGAGACNCTTTACTCCC AATCCAAAAGCAGATGCTTGCANANGAACTCANTNCTACAAGATTCATAN NNCTTACCCCCTANNTGCNCANATGGGNTCNAATNNNNACAAGAANCTN AANNCTACCCNNNNAAAAANANANNTNNGGGCCAATTNCNANANNANG GNGGNCNNT ACCNTGGGAANCCAACNCNNT ACCNAGCNTTNCNNCNNAC TTGGGGANTNTANTAGGGGACCCCAACTNCGTGGCNNAATNANNGGCAN AACTGGNTNCNNNGTGNAAGTGGCTTACNGTCNCAAGTNCACACAAGAT ACCANCCGGNACCCTTAANAGNTAAGNCNCGGGTGCCTTATNANGGNAC CTACCNACCTTAAANGNNTTGNGCTCAACCCCCGGTTTCCAATGGGGGAA CCTNGCCNCCNAATTGGNTTANGGATCCNGNCCCCTCCNNGAAAAGGAA NCTGGNGATCNGCGCNTTTACGGATCCTNCCNACCTNNNTNATAAGGCTN NNTCCNTTTTGNTCNNNNATNCGGTTTCNCCCNCTCNN

clone b:

GCGCCCGAGTNACTCCAGGCNCNACGTTGCNNTCTACTGCCTGCTCGAGC GGCCCCCACTNACTATAGATNCNATACAGAACCCTCNCTTAGCCTNCTCN NNCCNGGNNGNNCTTACATNGGGGGNNGGAACTCACAANCTNAGNNNGC TTCCTGANAACCTTTTAACAGTCATGTNCTGTNNCTTNCAAAGGANGCAA ANTTGCTACTTCCNTATTTGGCATGATAATCAAATGAAAAATNACTAAAA AGTNAANTTACATGTNTNCNCNTTTGGANTGNTGTCNACAAATTTATGAG CATGCTATTTNNACTAATGCCNTCANANNTTNTTAGAACTTAATNAACAN GNGCTGNNTTCAANTTTGANNNANNAAAANCTTANAGNCCAATTCAACA CACTGNNNGNCGTTCTAGNGGATNCAAACTCTNNACCANGNNTGANGCA TAACTNGAGTANTCTATAANGGCACCNAAACNCCTTGCCGNANTCATNGC 
CATAGCTGNGTNCTGTNTNAAATTGNTTNCGCTCNCNATTCCACACANNA TACAANCCGGAACCNTAAANAATNAANNCTGGGGGCCTATTCANNGAGC TAACTCCNTTAATNGCNNTGGGCTCACTNCCCGNTTTCCAATNNGGGAAC CCTGCCCNCCAANTGCATTAATGAATNCNGCCCCNNTCNNNGANAGGGA NCTTGCNNNCCNGCNCTTTTCCGNTTCTNCNCCT

35 clone a:

AAGCTTCGACTGTTTATAGATAGTCTTAACATTTTTTATGCTTTGCAATAC ACATTGTTATGATTCTGAAACCTAGAATACCTTCTATAAATCACAAATAG AATAAAAACATAAAGGAGCTGGAGTATTTGTGATATGAAATATATAAGA AGGAAGTCTAGTAAAGGTGTCCACCACCACCCTTTAATCCCAGCACTTGG GAGACAGAGGCAGGCAGATTTCTGAGTTCGAGGACAGCCTGGTCTACAA AGTGAGTTCCTGGACAGCCAGGGCTACACAGAGAAACCCTGTCTCGAAA AAAAAAAAGCTTA

clone b:

AAGCTTTTTTTTTTTCAAATTGATTAATAAAATAGAAATTTTATTATACTTT GCATATCCTTAAAAATATGAAAAACAAGGCCAAAAGTTTAAAAACAGTTT TACAGATGTGCATGCTAACAATGGTTTAATACATTTCCAATTATATAAAAT ACATTATATAAAAGATGCCTAGATTTTTACATACATCAAGTGAATTAAAT AAAGCATTCATATATTTCTATGATCTAAGTGCAATATGCACATACGTAGA AAAAAAATACTGATTTCCTGACCAAAGCTTA

clone c: not able to edit

36 clone a:

GCCCGGTTCTCAGGCNCNACGGTGCCNTCTAATGCNTGCTCGAGCGGCCG CCACTGTNTATAGATANCTGCAGAANCCTCNCTTACCTTCTCTNACGGAC NGCTGTNTAATAATATTAGGNNGAAGGNGACCNNTAGCTATTATNTTATA TNANGAGAAAGTTCTTCTGANGATCATNGGTTATTACANNGATANNAAGT TATCAGCANNTNAACCATATCTNATCTNACTTTATTGCTAGAGTTTATAGC ATTACAGGATTTCTTATTANNTTATTTNGGNAGAGTGATATAATTTGTTTT AAAACTGNGCCTTANCAATTGTTGAAAAAAAAAAAGCTTAANGGCGAAT TCCAGCACACTGGCGGCCGTTACTAGTGGATCCGAGCTCGGTACCAAGCT TGATGCATANCTTGAGTATTCTATAAGGGNACCNAAANAGNTTGGCGTAA TCATGGCCATAGCTGGNTNCTGTGTGAAATTGNTANCCGCNCACGATTCC ACACANNATACAANCCCGGACNNTAAAGNGTNAAGCCTGGGGTGCCTAA TGAGTNAGCTNACTCCCTTAATTGCGNNGCGCTCACTGNCCGGTNTCCAA TNGGGAAACCTGNCNCCNACTGNTTAANGNNTCNGCCNCCCNNCNNNGA NAGGCNNCTGNNNNNCGGNCNNCNTTTNNGNNTCCTNNCTNNCTGNNTN NNTGGC 
clone b:

TGTTTGTGCCCGNTNCTNAGNCNCNACGGTGCCNTCTACTGCCTGCTCGA GCGGCCGCCANTGCTATNGNTATCTGCAGAANCCTCNCTTAANCTTCTCN CACGGACNGCTGTNTAATAATATTAGGNAAAAGGNGANCNGTAGCTATT ATGNTATATNANGNGAAAGTTCTTCTGANGATCATNGGTTATTACANNGA TANNAAGTTATCAGGANNTNAACCNTATCTTATCTCACTTTATTGCTAGAG TTTATAGCATTACAGGATTTCTTATTAGNTTATTTNGGNAGAGTGATATAA TTTGTTNNAAAACGGGCCTTANCANTTGTTGAAAAAAAAAAAGCTTAAGG GCGAATTCCAANACACTGNGGCCGTTACTAGNGGATCCNAGCTCGNTACC AAGCTTGANNGCATACTTGAGTATTCTATAANGGNACCNAAANNGCTTGG CGTAATCATGGCCATAGCTGGNTNCTGTGTAGAAATTGCATNCGCTCNCN ATNNCACNCAANATACAANCCCGGACCNTAAAGNGTAAAGCCTGGGGTG CCTAATGAGTGANCTTACTNACATTAATTGCGNTGNGCTCACTGNCCGNT TTCCANTGGGGAACCTNCNNCCNANTTGCTTNATGAATNNNGCCCNNNTN CNGNGANAGGNNNCT

clone c: not available

39 clone a:

AAGCTTTGGTCAGGATAGATGGTGTGAAACTGATAAGAGGTTTTGGATGT GAAAAAGAGTTTCCAAAAGAATGGTGTCTGGGAGTTTGAATGTGATGATT AAAAAAAGAGCCAAGGAAAAAGGTAGCTAGAAAAAAAGGTTGGCTCTCA TCAGCCTTAATTTTGGAAAGCAGCTACTTACCCCTCAGAGAATAAAGTAT TATGCATTCTTGTCAATTTGAAAAAAAAAAAGCTTA

clone b: not available

clone c: not available

40 clone a:

AAGCTTTTTTTTTTTCCAAGGCATAAGAATAAGGTTTAATGCTGCACCCAT CAAGGCAGCCCTAGTGTCTGTCAACATGGAAGCTCCCTGAGCGGTGCAGA CCTCTCCAGTGTCCAGCTTCCTCAGTGTCTTCCACAGGACTACGCTGTGTC TGAGGCCTCGGCACATGGTACCATCGAGGCCTGTGGTGGGGGAGGGGCT

clone b:

AAGCTTTTTTTTTTTCAATTGAGGTAAACACATAGAATATCTAACATGAAA CAATTAAAAGACCGAACTCTGTACGAAGTTTGTTACAGTATTCTCTTGCTC 
CTTTTTATCCCCCAAGCTTTGAGTTCCTGATAGAATCCTACTTATGGTGCA ACGACCATGAATAACTTGTGTGTGTGTGTGTGTGTATGNGCGNNGANAAN CTTA

clone c:

AAGCTTTTTTTTTTTCCAAGGCATAAGAATAAGGTTTAATGCTGCACCCAT CAAGGCAGCCCTAGTGTCTGTCAACATGGAAGCTCCCTGAGCGGTGCAGA CCTCTCCAGTGTCCAGCTTNCTCAGTGTCTTCCACAGGACTACNCTGTGNN TGNNGCCTCGNCACATGGTACCATNNANNCCTGTGGNGG

44 clone a:

AAGCTTAGTAGGCAAAAAGACAAGTATCTGGAAACAAGAACACAGCGCC TTAGAGTAAAGGAGGAAAGACTGGGACATCACCTGACTGTGGTTGNNNT ACAGGNGA

clone b: not able to edit

clone c:

AAGCTTAGTAGGCAAAAAGACAAGTATCCGGAAACAAGAACACAGCGCC TTAGAGTAAAGGAGGAAAGACTGGGACATCACCTGACTGTGGTTGTTTTA CAGGGGATCTTCAGAGCTGTTGAGATCATTAAAGCATTAAACCTGCATTG TAGGTTGNTAACTGATTTTTCATAACACGCTTCAATGCTTTTACTAATCCT AGTAATTGTTAATGNCACTTGNGAAGATGNACAATTNCAGTANNTNATNT TANATATTTANATTATTANACCTTTTATATTANNTG

47 clone a:

AAGCTTGCACCATGAGATGTTATTTATTCAGCTAGGCGGGGCTCGAGCCA GGCCCTGCCCCTAGGTGAGCAGCCGCCACCTGGACAGGGACTGTCCTGTC ACCACTCACCCTCCAGCCAGCCTGTCTGTCAGGAAGATCTTCCTAGCCCTT TTTTAAAGCCTCTTTTACATTTTTTAAAAACATAACTTTTTCAGAGAGAGA GGGGAGCTGACAATCACTTTTCTTCTGTTTTGGTTTTTGGTTTTGGTTTTGT TTTGAAAGCCGTTTAAAGCTCAGTTCTGATGATCTATGCAGCTCTAAGTTT CCTCATGGAGCCTCACAGATCCAGTTTTGGGAAAGGATTTGGACTCAAAA CTAACTGACCAATTCTTTGCCCTTTGTACCAAGAGACTGATACTTANGCCC AGGAAATAAATGCTGGTGGTTTGNGAAAAAAAAAAAGCTTA

clone b:

NAGNNTGNNCCNTTTGNAAAGGGGTACTNTTGGATTCCNGNTGGACNNA AATCACNTGAATAAAAGNTCCNTNCTGGGNGCTNATTTGNGGGGGGGNG GGCTNAAGTGTGTACCAAGAATTGGGTGGNGGNNACAGAGACACACCCC 
CTCTNTGACACAACCCTCCTTTNCCCCGAAANTAAATGCGNGNNTTTATNT AAAACNCAACNTTNTGTGGAGANCCANANAATAAATTTGTNAAACANAA GNTTNCTGTGTGACCCCNGNAANGGGTATNCNATNNTATNTTTNTNGNAN ACTGTGTGTCNTATATGGGAAAAAGNTCTCTAACCNNGTGTTTGTGGNGG CNCCNCATGGGTAGAANATTNANACTGNTNCCCATTAAAANNTGAAGAA CTTNTTGGTGNATGAAAAAAAANACNCCTCTTCTCAAAAAAAAAAANTTN TTGGNGGATNTCTCCACCNNGTGGCGGNNCTAATTGGAGCCCCCTCCTNC CCCNNTNTTGATAATTTGGNGANTTTNTTTGGCCCAAATNANTTGGNGGG ANTATGTGTNNTTGTTNCTGGGGAAANTGTTNTCCNCTCCAATTCCCCANA TACANCCGGAGNTAAAGNNNAANCNTGGG

clone c: not available 


\section{Appendix B}

Alignment: 10 day old male pancreas cDNA, SPC12, and 28.

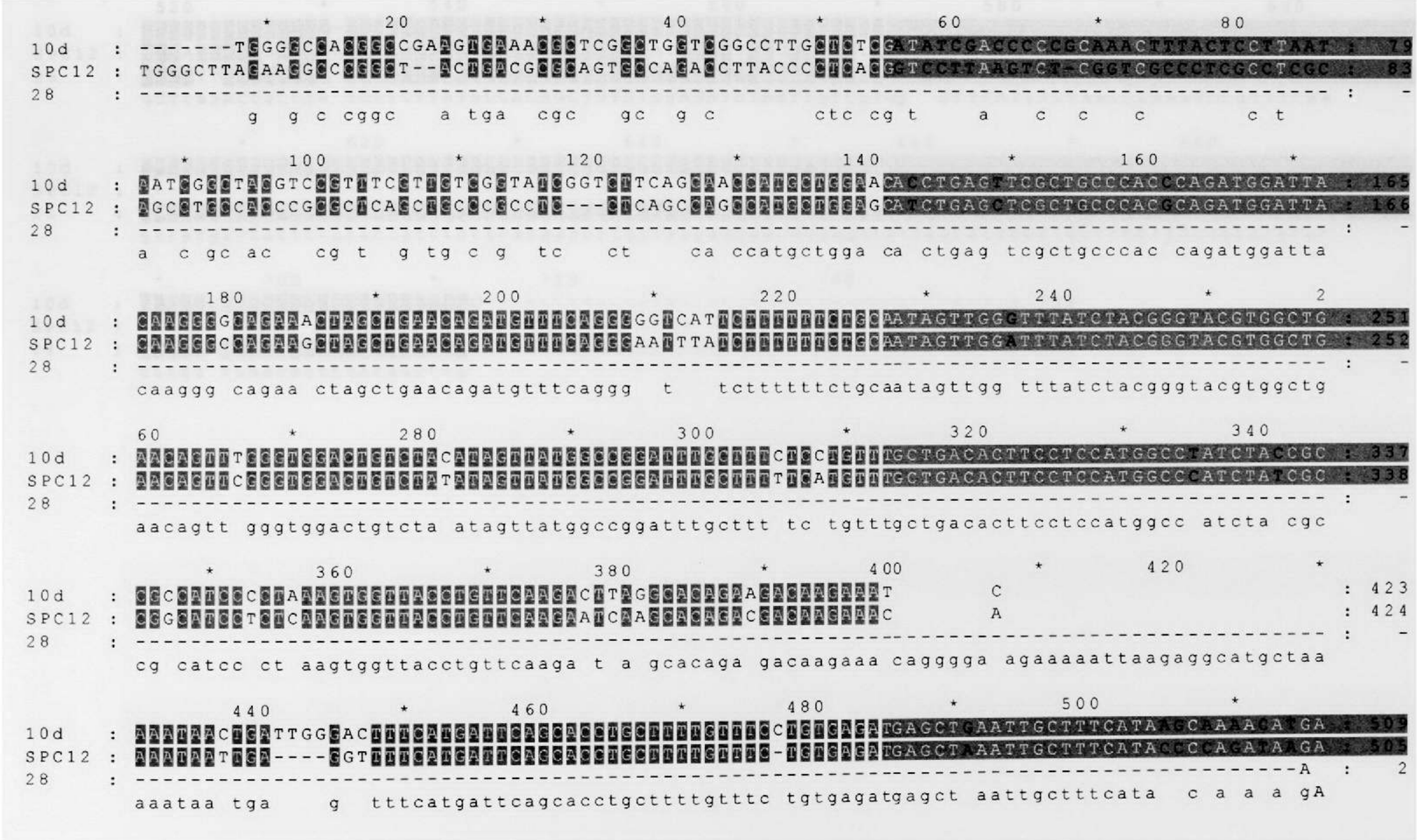




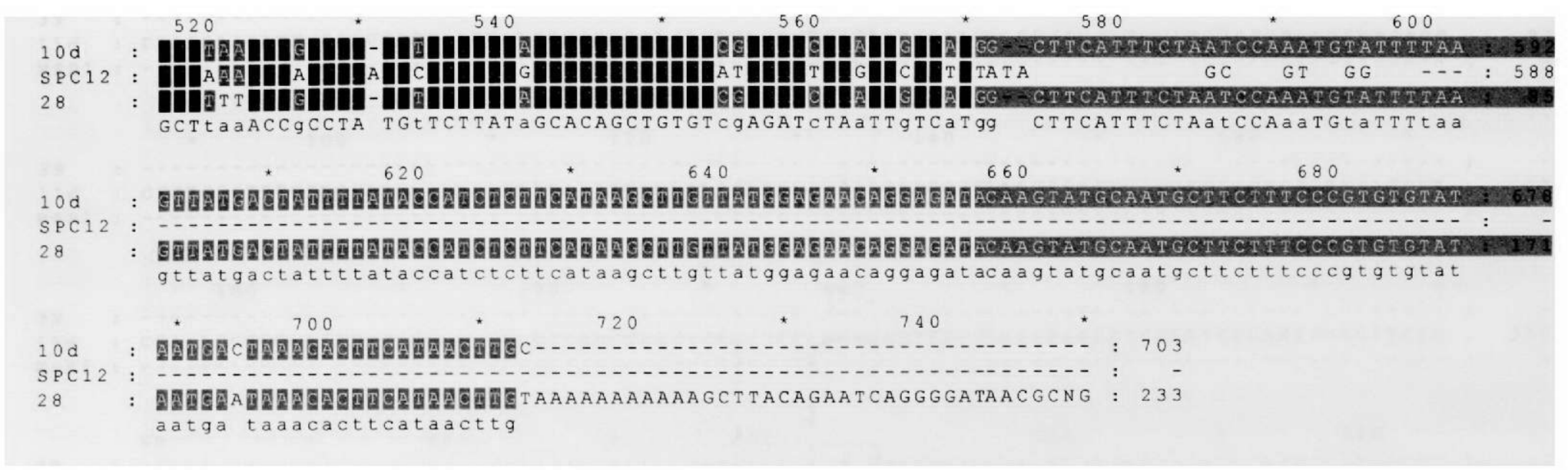




\section{APPENDIX C}

\section{Alignment: 39, 11d embryo cDNA and WSB1}

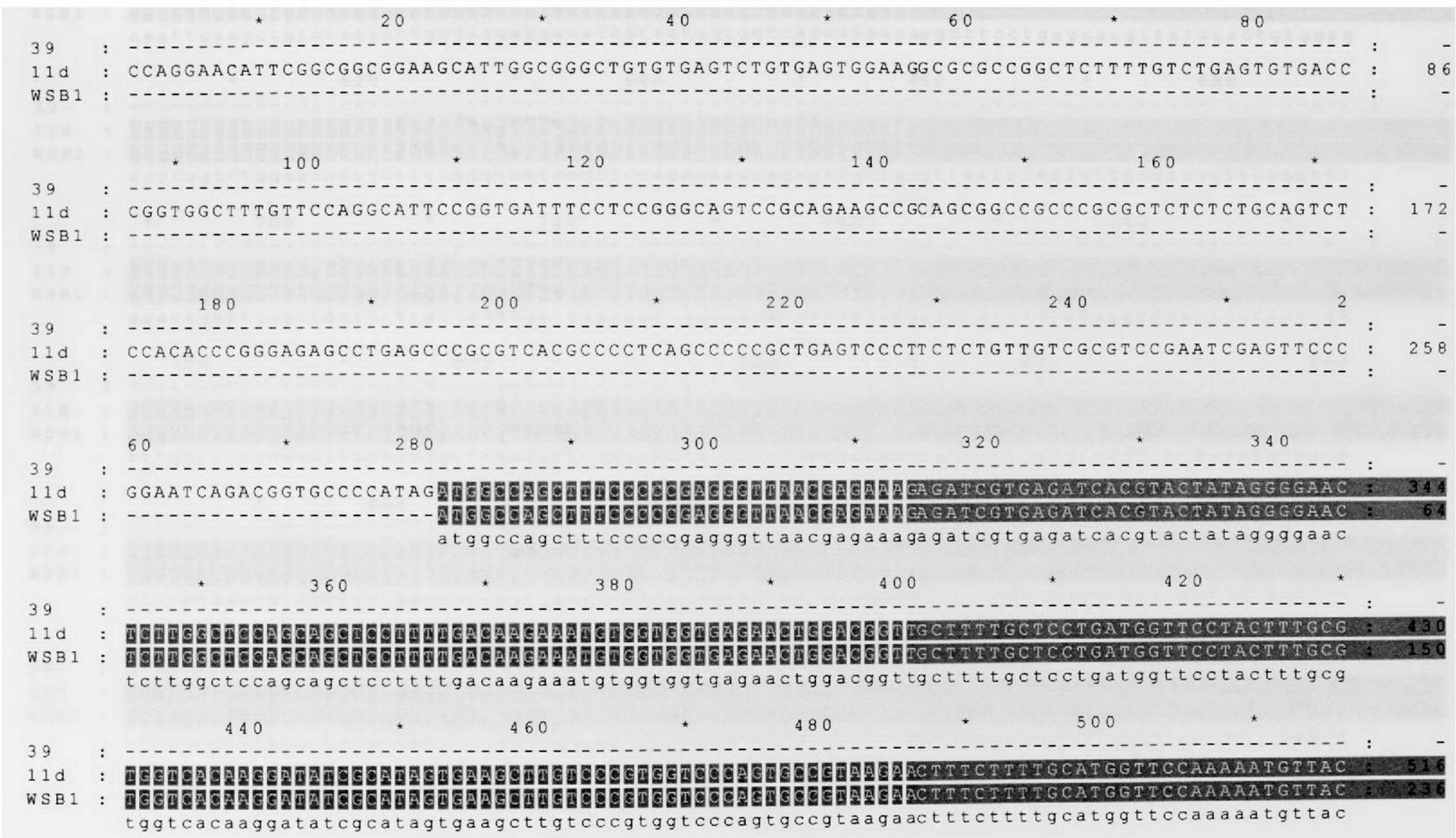


$39: 51 \mathrm{~d}:$ a

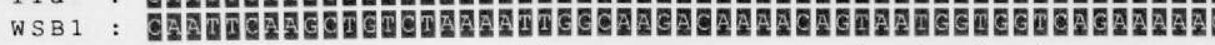

caattcaagctgtctaaattggcaagacaaacagtaatggtggtcagaaaacagcctcctgagcacgttatagactgtggag

$$
620
$$$$
640
$$

660

680

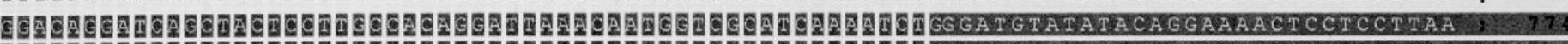

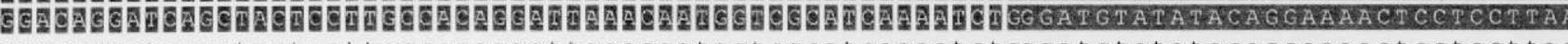
ggacaggatcagctactccttgccacaggattaaccatggtcgcatcaaatctgggatgtatatacaggaaactcctccttaa 800 840

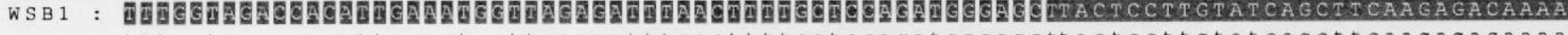

tt tggtagaccacattgaa atggttagagatttaacttttgctccagatgggagcttactccttgtatcagct $c$ a a gagacaaa 880 900 920 940

$39: 5$.

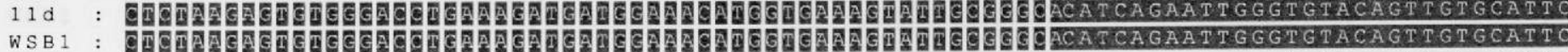
ctctaagagtgtgggacctgaaagatgatggaacatggtgaagtattgcgggcacatcagattgggtgtacagttgtgcattc 960 980 1000 1020 
$39:$ : 119

W B gctggaagtcatcaccatgatgttgtagcttgtgactttctcctgatggagcattgctagctactgcatcctatgacactcgtg

20 1140

1160

1180

1200

\section{MG}

tgtatgtctgggatccacacaatggagaccttctgatggagtttgggcacctgtttccetcgcccactccatatttgctggagga

$$
1220
$$$$
1240
$$

1280

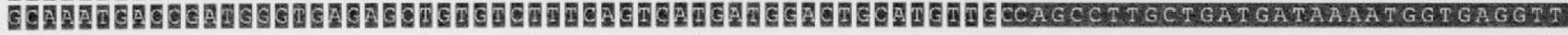

gcaatgaccgatgggtgagagctgtgtctttcagtcatgatggactgcatgttgccagccttgctgatgataaatggtgaggtt 1300 1320 1340 1360

90E

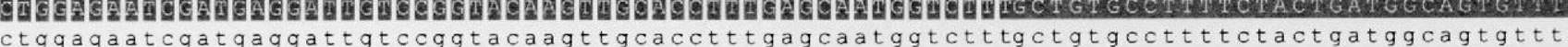

1380

1400

1420

1440

1460

$39: 50$.

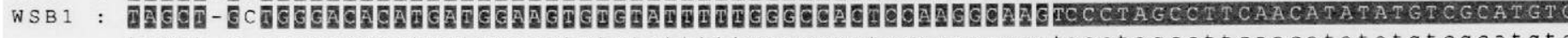
tagct g tgggacacatgatggaagtgtgtattttgggccactccaaggcaagtccctagcctcaacatatatgtcgcatgtc

1480

1500

1520

1540 


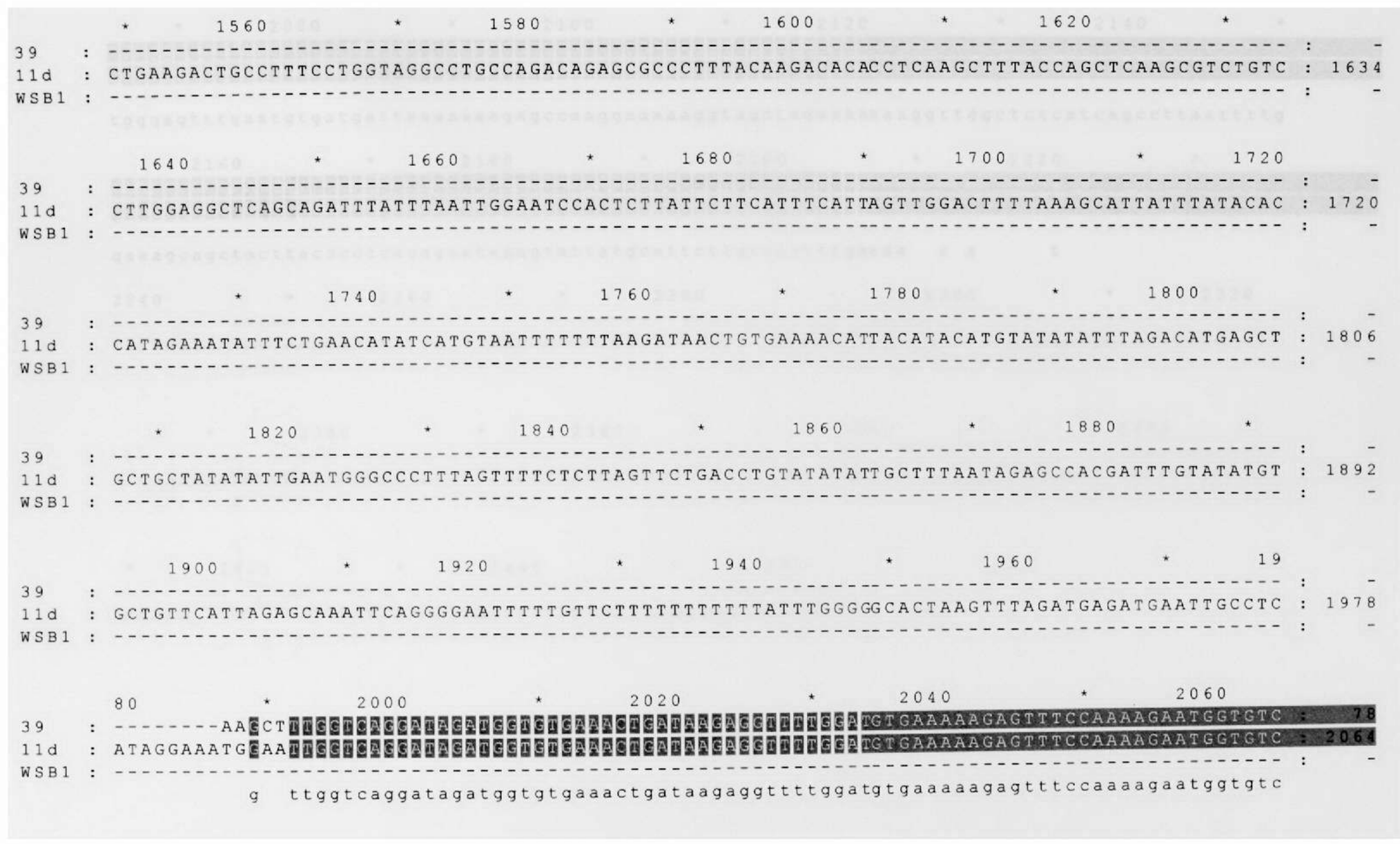




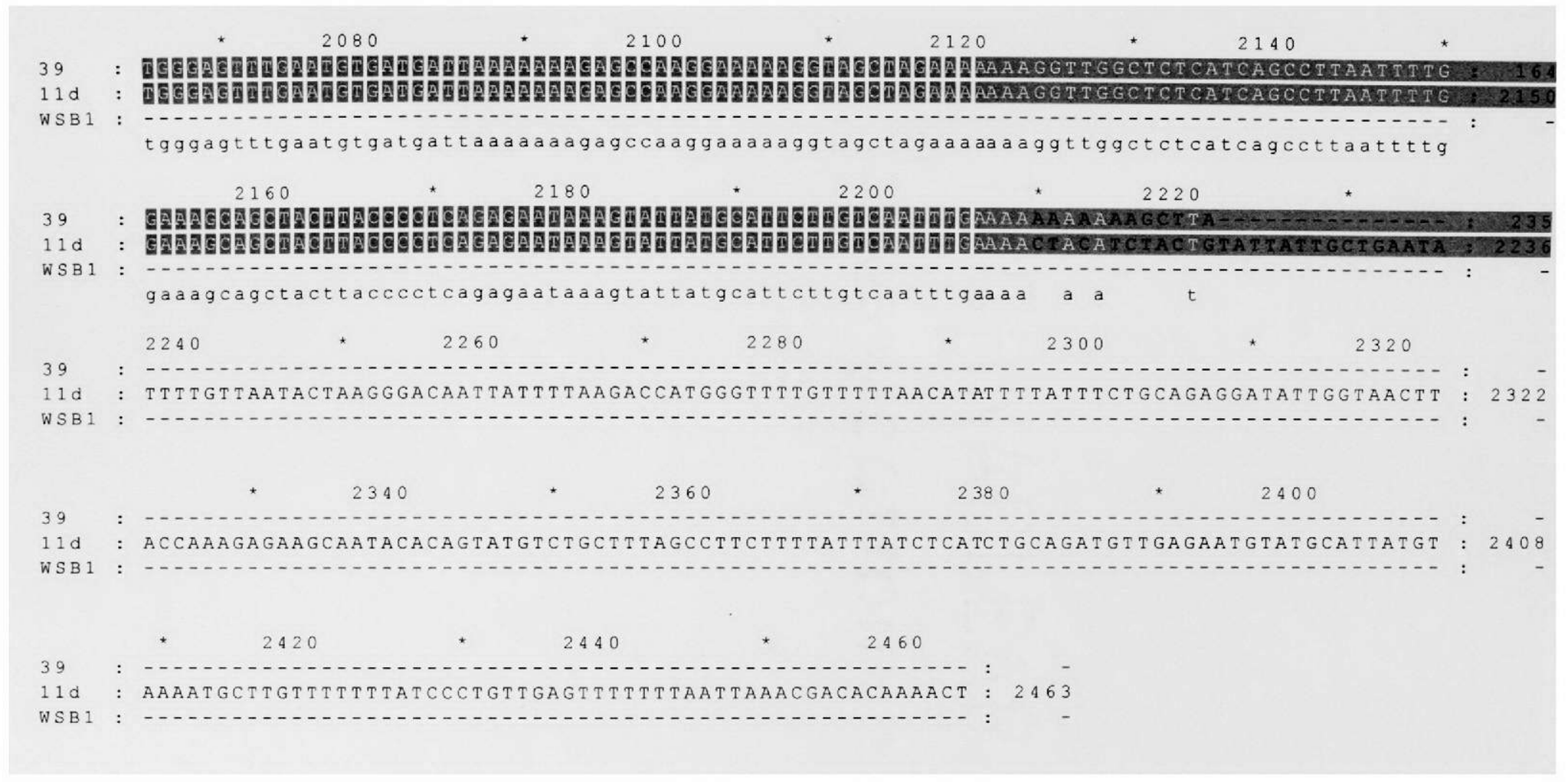

